\title{
Nitrate transboundary heavy pollution over East Asia in winter
}

\author{
Syuichi Itahashi ${ }^{1}$, Itsushi Uno ${ }^{2}$, Kazuo Osada $^{3}$, Yusuke Kamiguchi ${ }^{3, a}$, Shigekazu Yamamoto ${ }^{4}$, Kei Tamura $^{5}$, \\ Zhe Wang $^{2,6}$, Yasunori Kurosaki ${ }^{7}$, and Yugo Kanaya ${ }^{8}$ \\ ${ }^{1}$ Environmental Science Research Laboratory, Central Research Institute of Electric Power Industry, 1646 Abiko, \\ Abiko-shi, Chiba 270-1194, Japan \\ ${ }^{2}$ Research Institute for Applied Mechanics, Kyushu University, 6-1 Kasuga Park, Kasuga, Fukuoka 816-8580, Japan \\ ${ }^{3}$ Graduate School of Environmental Studies, Nagoya University, D2-1 (510) Furo-cho, Chikusa-ku, Nagoya, \\ Aichi 464-8601, Japan \\ ${ }^{4}$ Fukuoka Institute of Health and Environmental Sciences, 39 Mukaizano, Dazaifu-shi, Fukuoka 818-0135, Japan \\ ${ }^{5}$ Nagasaki Prefectural Environmental Affairs Department, 2-1306-11 Ikeda, Omura, Nagasaki 856-0026, Japan \\ ${ }^{6}$ Institute of Atmospheric Physics, Chinese Academy of Sciences, 40 Huayanli, Chaoyang, Beijing 100029, China \\ ${ }^{7}$ Arid Land Research Center, Tottori University, 1390 Hamasaka, Tottori 680-0001, Japan \\ ${ }^{8}$ Japan Agency for Marine-Earth Science and Technology, 3173-25 Showa-machi, Kanazawa-ku, Yokohama, \\ Kanagawa 236-0001, Japan \\ apresent address: JCB Co. Ltd., Tokai Regional Office, 2-16-26, Nishiki, Naka-ku, Nagoya, Aichi 460-0003, Japan
}

Correspondence to: Syuichi Itahashi (isyuichi@ criepi.denken.or.jp)

Received: 3 October 2016 - Discussion started: 14 November 2016

Revised: 13 February 2017 - Accepted: 27 February 2017 - Published: 20 March 2017

\begin{abstract}
High $\mathrm{PM}_{2.5}$ concentrations of around $100 \mu \mathrm{g} \mathrm{m}^{-3}$ were observed twice during an intensive observation campaign in January 2015 at Fukuoka $\left(33.52^{\circ} \mathrm{N}, 130.47^{\circ} \mathrm{E}\right)$ in western Japan. These events were analyzed comprehensively with a regional chemical transport model and synergetic ground-based observations with state-of-the-art measurement systems, which can capture the behavior of secondary inorganic aerosols $\left(\mathrm{SO}_{4}^{2-}, \mathrm{NO}_{3}^{-}\right.$, and $\left.\mathrm{NH}_{4}^{+}\right)$. The first episode of high $\mathrm{PM}_{2.5}$ concentration was dominated by $\mathrm{NO}_{3}^{-}$ (type $\mathrm{N}$ ) and the second episode by $\mathrm{SO}_{4}^{2-}$ (type $\mathrm{S}$ ). The concentration of $\mathrm{NH}_{4}^{+}$(the counterion for $\mathrm{SO}_{4}^{2-}$ and $\mathrm{NO}_{3}^{-}$) was high for both types. A sensitivity simulation in the chemical transport model showed that the dominant contribution was from transboundary air pollution for both types. To investigate the differences between these types further, the chemical transport model results were examined, and a backward trajectory analysis was used to provide additional information. During both types of episodes, high concentrations of $\mathrm{NO}_{3}^{-}$ were found above China, and an air mass that originated from northeast China reached Fukuoka. The travel time from the coastline of China to Fukuoka differed between types: it was $18 \mathrm{~h}$ for type $\mathrm{N}$ and $24 \mathrm{~h}$ for type $\mathrm{S}$. The conversion ratio of $\mathrm{SO}_{2}$ to $\mathrm{SO}_{4}^{2-}\left(F_{\mathrm{S}}\right)$ was less than 0.1 for type $\mathrm{N}$, but reached
\end{abstract}

0.3 for type $S$ as the air mass approached Fukuoka. The higher $F_{\mathrm{s}}$ for type $\mathrm{S}$ was related to the higher relative humidity and the concentration of $\mathrm{HO}_{2}$, which produces $\mathrm{H}_{2} \mathrm{O}_{2}$, the most effective oxidant for the aqueous-phase production of $\mathrm{SO}_{4}^{2-}$. Analyzing the gas ratio as an indicator of the sensitivity of $\mathrm{NO}_{3}^{-}$to changes in $\mathrm{SO}_{4}^{2-}$ and $\mathrm{NH}_{4}^{+}$showed that the air mass over China was $\mathrm{NH}_{3}$-rich for type $\mathrm{N}$, but almost $\mathrm{NH}_{3}-$ neutral for type $\mathrm{S}$. Thus, although the high concentration of $\mathrm{NO}_{3}^{-}$above China gradually decreased during transport from China to Fukuoka, higher $\mathrm{NO}_{3}^{-}$concentrations were maintained during transport owing to the lower $\mathrm{SO}_{4}^{2-}$ for type $\mathrm{N}$. In contrast, for type $\mathrm{S}$, the production of $\mathrm{SO}_{4}^{2-}$ led to the decomposition of $\mathrm{NH}_{4} \mathrm{NO}_{3}$, and more $\mathrm{SO}_{4}^{2-}$ was transported. Notably, the type $\mathrm{N}$ transport pattern was limited to western Japan, especially the island of Kyushu. Transboundary air pollution dominated by $\mathrm{SO}_{4}^{2-}$ (type $\mathrm{S}$ ) has been recognized as a major pattern of pollution over East Asia. However, our study confirms the importance of transboundary air pollution dominated by $\mathrm{NO}_{3}^{-}$, which will help refine our understanding of transboundary heavy $\mathrm{PM}_{2.5}$ pollution in winter over East Asia. 


\section{Introduction}

Particulate matter (PM) presents major environmental problems globally, especially in East Asia. A typical example is the episode of severe air pollution that occurred in January 2013 above China (e.g., Wang et al., 2014; Uno et al., 2014). During this episode, PM with aerodynamic diameters of less than $2.5 \mu \mathrm{m}\left(\mathrm{PM}_{2.5}\right)$ reached record-breaking concentrations of $772 \mu \mathrm{g} \mathrm{m}^{-3}$ on 12 January 2013 (Y. Pan al., 2016). Transboundary air pollution in downwind regions resulting from the severe air pollution in China is also an important environmental problem. For example, the possible long-range transport of $\mathrm{PM}_{2.5}$ was based on the comparison of observations in metropolitan areas and remote islands in western Japan (Kaneyasu et al., 2014). They highlighted the dominant effect of the transboundary transport of sulfate $\left(\mathrm{SO}_{4}^{2-}\right)$ as a major $\mathrm{PM}_{2.5}$ component in western Japan throughout most of the year. In spring, due to the prevailing westerly wind over East Asia, the transboundary air pollution of both aerosols and gases, e.g., carbon monoxide (CO) and ozone $\left(\mathrm{O}_{3}\right)$, has been thoroughly discussed (Itahashi et al., 2010, 2013, 2015; Kanaya et al., 2016; Nagashima et al., 2010). In summer, the clean air mass from the oceans is moved over Japan by the southerly wind caused by the Pacific High; however, some studies have discussed the importance of transboundary air pollution from China over western Japan (Itahashi et al., 2012; Ikeda et al., 2014). Recently, 1-year source-receptor relationships for $\mathrm{SO}_{4}^{2-}$ were evaluated, and China was identified as the main influence on downwind regions throughout the year with local sulfur dioxide $\left(\mathrm{SO}_{2}\right)$ emissions making an important contribution in summer (Itahashi et al., 2017). Compared with the analyses for spring and summer, transboundary air pollution events in winter are less well understood.

In this study, we also focused on nitrate $\left(\mathrm{NO}_{3}^{-}\right)$, which is an important $\mathrm{PM}_{2.5}$ component. The $\mathrm{NO}_{3}^{-}$in $\mathrm{PM}_{2.5}$ is produced via the reaction of gas-phase nitrate (nitric acid; $\mathrm{HNO}_{3}$ ) and ammonia $\left(\mathrm{NH}_{3}\right)$, and this process is reversible. The reaction favors a shift toward the aerosol phase at low temperatures and high humidity (Seinfeld and Pandis, 2006). The simulated spatial distribution over East Asia showed the possible impact of transboundary $\mathrm{NO}_{3}^{-}$pollution in winter over western Japan (Zhang et al., 2007; Ying, 2014). However, a quantitative evaluation over downwind regions was not presented in previous studies. This is partly because the model ability was not evaluated owing to the difficulty in measuring $\mathrm{NO}_{3}^{-}$. Particulate $\mathrm{NH}_{4} \mathrm{NO}_{3}$ may be volatilized after collection on the filter, either through an increase in the pressure drop across the particle-collecting medium or changes in the gas-aerosol equilibrium during sampling (Sickles II et al., 1999; Chang et al., 2000). This volatilization could occur even in winter because the temperature in the instrument shelter can be increased by heat from the pump. Therefore, the ground-based Acid Deposition Monitoring Network in East Asia uses the four-stage fil- ter pack method: $\mathrm{NH}_{4} \mathrm{NO}_{3}$ is collected on the first filter and gas-phase $\mathrm{HNO}_{3}$ and $\mathrm{NH}_{3}$ are detected on the subsequent filters. The artifacts might not be significant; however, to avoid the possibility of volatilization, total nitrate (the sum of $\mathrm{NO}_{3}^{-}$ and $\mathrm{HNO}_{3}$ ) has been used to evaluate the model ability in previous studies (e.g., Kajino et al., 2013).

To improve our understanding of the behavior of $\mathrm{NO}_{3}^{-}$, accurate measurements and the evaluation of the model ability are needed. In this study, we used a state-of-the-art automated monitoring system for $\mathrm{SO}_{4}^{2-}$ and $\mathrm{NO}_{3}^{-}$, an aerosol chemical speciation analyzer (ACSA). This system measures $\mathrm{SO}_{4}^{2-}$ and $\mathrm{NO}_{3}^{-}$with high temporal resolution, and $1 \mathrm{~h}$ intervals were used in this study, minimizing the possibility of volatilization. In addition, the behavior of ammonium $\left(\mathrm{NH}_{4}^{+}\right)$, which is the counterion for $\mathrm{SO}_{4}^{2-}$ and $\mathrm{NO}_{3}^{-}$, was captured by the well-validated $\mathrm{NH}_{x}$ monitoring system. Therefore, the secondary inorganic aerosols (sulfate $\left(\mathrm{SO}_{4}^{2-}\right)$, nitrate $\left(\mathrm{NO}_{3}^{-}\right)$, and ammonium $\left(\mathrm{NH}_{4}^{+}\right)$; hereafter summarized as SNA) were fully observed by our synergetic monitoring system. The denuder filter pack (D-F pack) method with 6-8 $\mathrm{h}$ cycles was also used during the intensive observation period from 7-17 January 2015. This intensive observation was designed to capture the heavy $\mathrm{PM}_{2.5}$ pollution episode in the wintertime and to support and validate the ACSA and $\mathrm{NH}_{x}$ monitoring systems. Based on these measurement systems, gas-phase $\mathrm{HNO}_{3}$ and $\mathrm{NH}_{3}$ can be measured by the D-F pack method and the $\mathrm{NH}_{x}$ monitor, respectively. The related gas-phase behavior analysis is valuable for improving our understanding of the formation of $\mathrm{NO}_{3}^{-}$. The observations were conducted at the Chikushi Campus of Kyushu University, which is in the suburbs of Fukuoka $\left(33.52^{\circ} \mathrm{N}\right.$, $130.47^{\circ} \mathrm{E}$ ) in western Japan. The synergetic ground-based observation dataset was systematically interpreted by using the regional chemical transport model, and we also examined the impact of the domestic and transboundary air pollution in winter. Chemical transport model studies are one type of critical approach for analyzing the behavior of threedimensional air pollutants and estimating source impacts. A systematic comparison of model results with observations, including gas-phase precursors, will promote understanding and improve the model ability for Asia. This will also contribute to the Model Intercomparison Study for Asia (MICSAsia), which focuses on providing a common understanding of the model performances and uncertainties, especially for models of long-range transport in Asia (Carmichael et al., 2002, 2008; Li et al., 2017). This paper is constructed as follows. Section 2 documents the observation dataset and the model simulation. Section 3 discusses the results with respect to the temporal variations at the observation sites and the model results combined with the backward trajectory analysis. Finally, a summary and conclusions are given in Sect. 4. 


\section{Observation and model simulation}

\subsection{Observation sites}

The synergetic observations for capturing SNA behavior were conducted at the Chikushi Campus of Kyushu University located in the suburbs of Fukuoka $\left(33.52^{\circ} \mathrm{N}, 130.47^{\circ} \mathrm{E}\right)$. Fukuoka is the largest center of commerce on the island of Kyushu. The population of Fukuoka is 1.5 million and that of the Fukuoka metropolitan area is 2.5 million. This is the fourth largest metropolitan area in Japan after Tokyo (34.8 million), Osaka (12.2 million), and Nagoya (5.5 million). This site is an urban site. In addition to the observations at Fukuoka, observations from the Goto Islands $\left(32.68^{\circ} \mathrm{N}\right.$, $\left.128.83^{\circ} \mathrm{E}\right)$ and Tsushima Island $\left(32.20^{\circ} \mathrm{N}, 129.28^{\circ} \mathrm{E}\right)$ were also used. The Goto Islands are located in the East China Sea, $190 \mathrm{~km}$ southwest of Fukuoka, and have a population of 70000 . Tsushima Island is located in the Tsushima Strait, $140 \mathrm{~km}$ northwest of Fukuoka, and has a population of 34000 . These islands have negligible anthropogenic emission sources and are regarded as remote sites. In addition to these three sites over Kyushu, to investigate the regions affected by transboundary air pollution, observations from Tottori $\left(35.54^{\circ} \mathrm{N}, 134.21^{\circ} \mathrm{E}\right)$ in western Japan were also used. Tottori has a population of 190000 , and this site is also regarded as a remote site in western Japan. The locations of these four observation sites over Japan are shown in Fig. 1. In addition to these observations over Japan, $\mathrm{PM}_{2.5}$ observations in China from the US Embassy in Beijing and the US consulates in the provincial capitals of Shanghai and Shenyang were used. The locations of these three sites over China are shown in Fig. 2.

\subsubsection{Aerosol chemical speciation analyzer (ACSA)}

An ACSA-12 monitor (Kimoto Electric Co., Ltd., Osaka, Japan) for $\mathrm{PM}_{10}$ and $\mathrm{PM}_{2.5}$, which were separated by a US Environmental Protection Agency inlet and a virtual impactor, were measured with high temporal resolution (Kimoto et al., 2013). PM was collected on a tape filter made of Teflon (PTFE). Hourly observations were conducted for $\mathrm{SO}_{4}^{2-}$ and $\mathrm{NO}_{3}^{-}$at Fukuoka. The mass concentrations of PM were determined by using the beta ray absorption method. The ACSA-12 measured $\mathrm{NO}_{3}^{-}$using an ultraviolet spectrophotometric method and $\mathrm{SO}_{4}^{2-}$ by turbidimetry after the addition of $\mathrm{BaCl}_{2}$ to form $\mathrm{BaSO}_{4}$ and polyvinyl pyrrolidone as a stabilizer. The analytical period was within $2 \mathrm{~h}$ of sampling; therefore, the volatilization of particulate $\mathrm{NH}_{4} \mathrm{NO}_{3}$ after collection was regarded as small compared with the traditional filter pack observation method. An ACSA has been tested (Osada et al., 2016) and used to analyze the severe winter haze in Beijing (Zheng et al., 2015; Li et al., 2016) and to identify the aerosol chemical compositions at Fukuoka (X. Pan et al., 2016).

\subsection{2 $\mathrm{NH}_{x}$ monitor}

The behavior of $\mathrm{NH}_{3}$ and $\mathrm{NH}_{4}^{+}$is also important because they are the counterions for $\mathrm{SO}_{4}^{2-}$ and $\mathrm{NO}_{3}^{-}$. The concentrations of gaseous $\mathrm{NH}_{3}$ and aerosol $\mathrm{NH}_{4}^{+}$were measured with a semicontinuous microflow analytical system $\left(\mathrm{MF}-\mathrm{NH}_{3} \mathrm{~A}\right.$; Kimoto Electric Co., Ltd.; Osada et al., 2011) at Fukuoka. The atmospheric $\mathrm{NH}_{x}$ was dissolved in ultrapure water with a continuous air-water droplet sampler and quantified by fluorescence (excitation, $360 \mathrm{~nm}$; emission, $420 \mathrm{~nm}$ ) of the $o$ phthalaldehyde-sulfite- $\mathrm{NH}_{3}$ reaction product (Genfa et al., 1989). Two inlet lines were used to differentiate the total amounts of $\mathrm{NH}_{x}$ and particulate $\mathrm{NH}_{4}^{+}$after gaseous $\mathrm{NH}_{3}$ was removed by a phosphoric acid-coated denuder from the sample air stream. The cutoff diameter of the inlet impactor was about $2 \mu \mathrm{m}$.

\subsubsection{Denuder filter pack method (D-F pack)}

During the intensive observation period from 7-17 January 2015, D-F pack measurements were conducted at Fukuoka to validate the ACSA and $\mathrm{NH}_{x}$ monitor measurement systems. An annular denuder multistage filter sampling system was used for $\mathrm{HNO}_{3}$ and size-segregated aerosol sampling. The sampling interval was $6-8 \mathrm{~h}$. At the inlet, coarsemode aerosols were removed by nuclepore membrane filters (111114; Nomura Micro Science Co., Ltd., Atsugi, Japan; pore size $8 \mu \mathrm{m}$ ), and then gas-phase $\mathrm{HNO}_{3}$ was collected with the annular denuder (2000-30x242-3CSS; URG Co., Chapel Hill, NC, USA) coated with $\mathrm{NaCl}$ (Perrino et al., 1990). Fine-mode aerosols were collected with a PTFE filter (J100A047A; ADVANTEC, Tokyo, Japan; pore size $1 \mu \mathrm{m}$ ), and a nylon filter (66509; Pall Co., Port Washington, NY, USA) captured volatized $\mathrm{NO}_{3}^{-}$from the PTFE filter (Appel et al., 1981; Vecchi et al., 2009). Because of the use of an annular denuder system before PTFE filter collection, the adsorption of $\mathrm{HNO}_{3}$, which would otherwise lead to the overestimation of $\mathrm{NO}_{3}^{-}$, was low. The sample airflow rate was $16.7 \mathrm{~L} \mathrm{~min}^{-1}\left(1 \mathrm{~atm}, 25^{\circ} \mathrm{C}\right)$. Under these conditions, the aerodynamic diameter of $50 \%$ cutoff for the nuclepore filter was about $1.9 \mu \mathrm{m}$ (John et al., 1983). The samples were analyzed by ion chromatography (IC). Comparing size-segregated $\mathrm{SO}_{4}^{2-}$ and $\mathrm{NO}_{3}^{-}$data based on the D-F pack method with data from the ACSA showed systematic differences. A linear regression analysis of fine-mode and coarsemode $\mathrm{SO}_{4}^{2-}$ and $\mathrm{NO}_{3}^{-}$showed good correlation, but the slope was not uniform. Fine-mode aerosols were underestimated by the D-F pack relative to the ACSA measurements, and coarse-mode aerosols were overestimated by the D-F pack relative to the ACSA measurements. However, by summing the fine- and coarse-mode data, the slope between the D-F pack and ACSA results was close to unity. The difference in the cutoff diameter of the D-F pack method was considered to be the most important factor in explaining the differences between the results from the D-F pack and the ACSA. More 

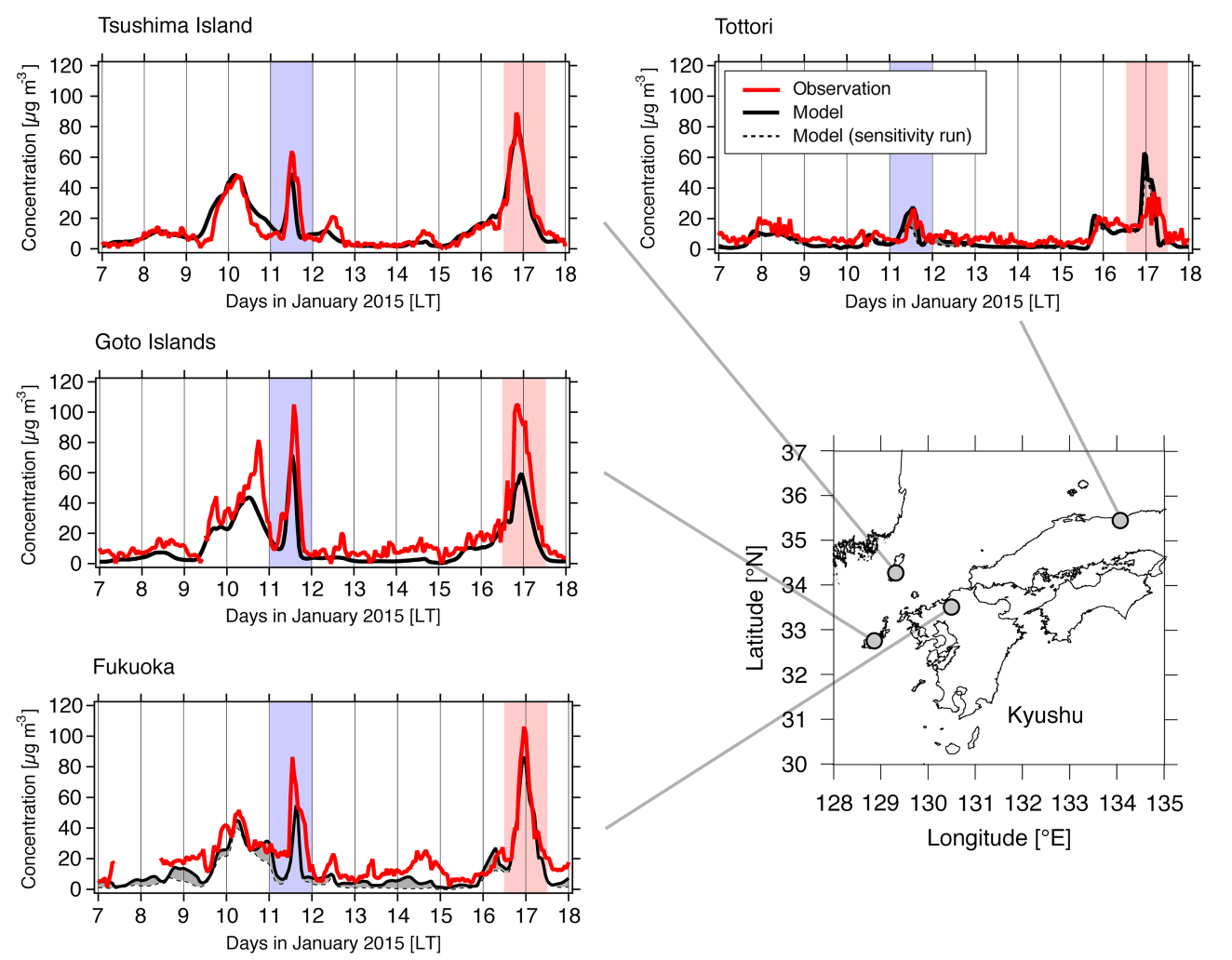

Figure 1. The temporal variation in $\mathrm{PM}_{2.5}$ over Japan at Fukuoka, the Goto Islands, Tsushima Island, and Tottori from 7-17 January 2015. The blue and red shading shows the episodes focused on in this study. The red lines indicate the observations. The black lines indicate the base case simulation, and the dotted black lines indicate the sensitivity simulation in which the anthropogenic emissions from Japan were switched off; the differences between these results, shown in gray, represent local contributions.

details of the comparison and validation of the ACSA data are reported in Osada et al. (2016).

\subsubsection{PM-712}

Hourly $\mathrm{PM}_{10}$ and $\mathrm{PM}_{2.5}$ concentrations were measured by a PM monitor (PM-712; Kimoto Electric Co., Ltd.) at the Goto Islands, Tsushima Island, and Tottori. The PM-712 used the beta ray attenuation method to measure the mass concentrations of $\mathrm{PM}_{10}$ and $\mathrm{PM}_{2.5}$. The ionic constituents of the species on the PTFE tape filters were also analyzed by IC to compare the aerosol behavior at Fukuoka and the other sites. At all sites, the sample spots collected on the tape filter were covered with polyester tape to avoid contamination and cross talk interference during storage. The sampling duration for the PM-712 tape filters was $1 \mathrm{~h}$, except for Tottori where it was $3 \mathrm{~h}$. For chemical analysis, four consecutive $1 \mathrm{~h}$ tape samples were combined into one sample for the Goto Islands and Tsushima Island. For Tottori, tape samples for 1 or 0.5 days were combined. Because of a temperature change during PM sample storage, some $\mathrm{NO}_{3}^{-}$may have escaped via volatilization of $\mathrm{HNO}_{3}$ from the sample. Therefore, $\mathrm{NO}_{3}^{-}$ data from the Goto Islands, Tsushima Island, and Tottori were not used. $\mathrm{NH}_{4}^{+}$is also affected by volatilization when it forms $\mathrm{NH}_{4} \mathrm{NO}_{3}$, but it preferentially forms $\left(\mathrm{NH}_{4}\right)_{2} \mathrm{SO}_{4}$. The data for $\mathrm{NH}_{4}^{+}$were used to indicate the concentration trapped by $\mathrm{SO}_{4}^{2-}$. Hereafter, we call these datasets from the PM tape samples "tape filters".

\subsubsection{Beta attenuation monitors (BAMs)}

Hourly $\mathrm{PM}_{2.5}$ concentrations in China were measured by beta attenuation monitors (BAMs) (1020; Met One Instruments, Inc., Grants Pass, OR, USA) at the US Embassy in Beijing on 8 April 2008, at the US consulates in Shanghai on 21 December 2011, and at the US consulates in Shenyang on 22 April 2013 (Ministry of Environment, 2016). In the BAM technique, PM is collected on a quartz filter tape over a given time interval and the attenuation of beta rays through the sample is measured and correlated directly with the PM mass. The details and the statistical analysis results of the BAM observation at the US Embassy and consulates are found in the work of San Martini et al. (2015).

\subsubsection{Multi-angle absorption photometer (MAAP)}

Observations of black carbon (BC), a primary aerosol that directly reflects local emission contributions, from Fukuoka 

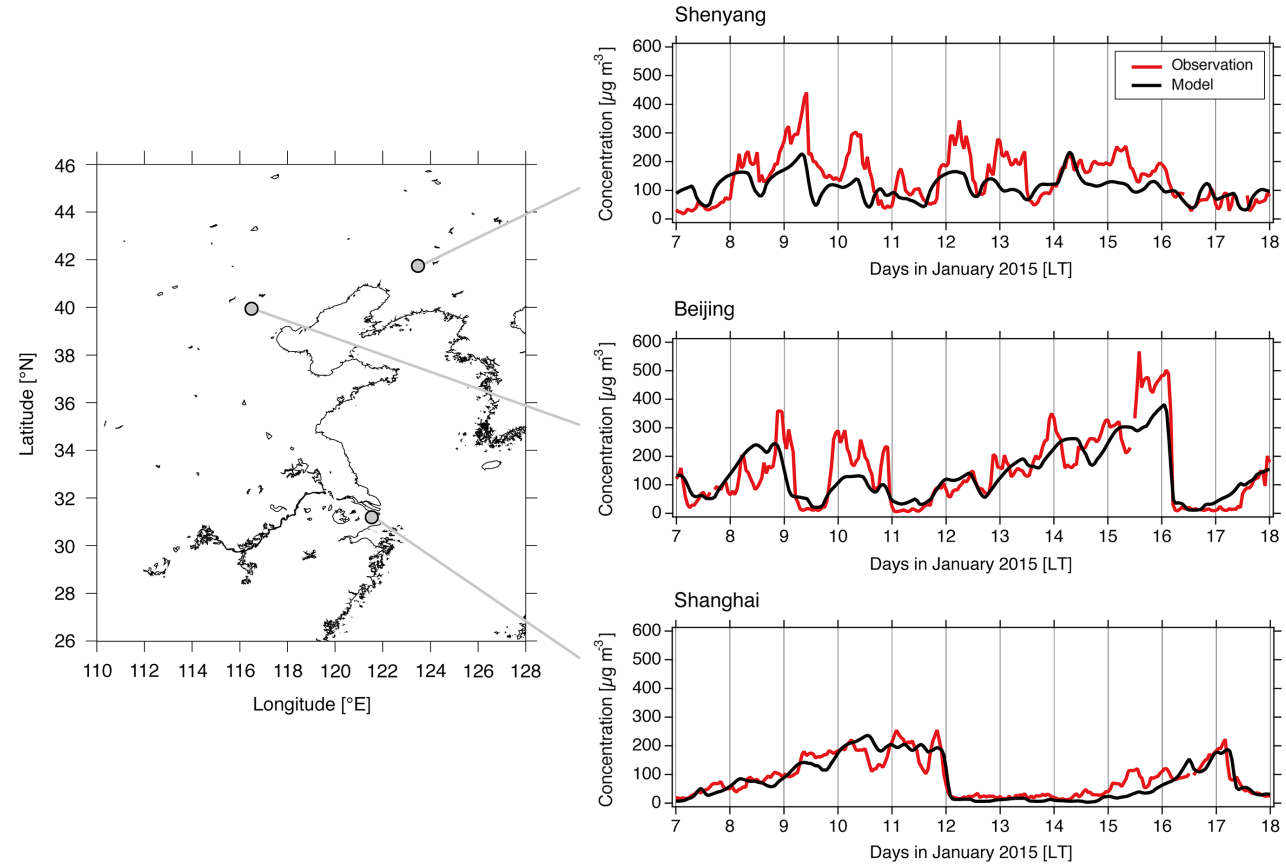

Figure 2. The temporal variation in $\mathrm{PM}_{2.5}$ over China at Beijing, Shanghai, and Shenyang from 7-17 January 2015. The red lines indicate the observations by the BAMs at the US Embassy in Beijing and at the US consulates in Shenyang and Shanghai. The black lines indicate the base case simulation.

and the Goto Islands were also used to distinguish domestic and transboundary air pollution. BC is observed by using a multi-angle absorption photometer (MAAP) (MAAP5012; Thermo Fisher Scientific, Waltham, MA, USA) (Petzold et al., 2005). In this method, the absorbance of the particles deposited on the filter is distinguished from scattering by reflectance measurements at multiple angles and by transmittance. This is to minimize the effects of coexisting aerosol particles other than $\mathrm{BC}$ on filter-based absorption photometers. The comparison measurements of $\mathrm{BC}$ from the Goto Islands were previously performed by Kanaya et al. (2013), and they reported that the BC MAAP measurements were strongly correlated with measurements by other techniques but had a positive bias. From the results reported by Kanaya et al. (2013), the MAAP absorption cross section of $6.6 \mathrm{~m}^{2} \mathrm{~g}^{-1}$ was systematically increased to $10.3 \mathrm{~m}^{2} \mathrm{~g}^{-1}$ at $639 \mathrm{~nm}$. There were no MAAP BC measurements from the Goto Islands before 11 January 2015 during the intensive observation period.

\subsection{Chemical transport model}

The chemical transport model simulation was performed by using the Community Multiscale Air Quality (CMAQ) modeling system version 4.7.1 (Byun and Schere, 2006) with nesting over East Asia. The meteorological fields of CMAQ were prepared with the Weather Research and Forecasting Model version 3.3.1 (Skamarock et al., 2008) with analysis nudging applied to the National Centers for Environmental
Prediction final operational global analysis data. The model domain covers the whole of East Asia with an $81 \mathrm{~km}$ horizontal grid resolution and a $95 \times 75$ grid centered at $30^{\circ} \mathrm{N}$ and $115^{\circ} \mathrm{E}$ on a Lambert conformal projection. The nested domain covers eastern China and the whole of Japan with a $27 \mathrm{~km}$ horizontal grid resolution and a $145 \times 145$ grid. The vertical grid for sigma-pressure coordinates extends to $50 \mathrm{hPa}$ with 37 layers with nonuniform spacing. The lateral boundary condition was as given by the global chemical transport model of Geos-Chem (Uno et al., 2014). The simulation period was from 1-17 January 2015, and the first 6 days were discarded as model spin-up time. The dry deposition velocity of $\mathrm{HNO}_{3}$ over land was increased by a factor of 5 based on the model intercomparison results (Shimadera et al., 2014; Morino et al., 2015).

Emissions were set as follows. Anthropogenic emissions and natural sources of $\mathrm{NO}_{x}$ from soil were obtained from the latest Regional Emission inventory in ASia (REAS) version 2.1 (Kurokawa et al., 2013), which covers 2000 to 2008. Therefore, the emissions for January 2008 were used in this study. This is because satellite observations of the $\mathrm{NO}_{2}$ column showed a decreasing trend in $\mathrm{NO}_{x}$ emissions from China of $-6 \% \mathrm{yr}^{-1}$ after 2011, and the levels for 2015 are similar to those for 2009 (Irie et al., 2016). In contrast, the $\mathrm{NO}_{2}$ column over Japan decreased until 2013, and then began to increase from 2013 owing to the change in power plant use after the Fukushima Daiichi nuclear disaster (Morino et al., 2011). The level of the $\mathrm{NO}_{2}$ column over Japan in 2015 
Table 1. The anthropogenic emission amounts used in this study. Units are Gg month ${ }^{-1}$ for January 2015.

\begin{tabular}{lrcr}
\hline & China & Republic of Korea & Japan \\
\hline $\mathrm{SO}_{2}$ & 2882.2 & 35.8 & 61.1 \\
$\mathrm{NO}_{x}$ & 2150.2 & 90.3 & 189.3 \\
$\mathrm{NH}_{3}$ & 642.1 & 15.0 & 15.3 \\
\hline
\end{tabular}

was close to that in 2008 (Irie et al., 2016). The installation of flue gas desulfurization systems in power plants in China decreased $\mathrm{SO}_{2}$ emissions in China from 2005 to 2006; after this turning point, $\mathrm{SO}_{2}$ emissions generally showed a decreasing trend but the variation in $\mathrm{SO}_{2}$ emissions is complicated (Xia et al., 2016). The assumption about the 2008 level of $\mathrm{SO}_{2}$ emissions may overestimate the actual status. In Japan, $\mathrm{SO}_{2}$ emissions are increasing for the same reasons as for $\mathrm{NO}_{x}$; however, there are no reliable references for the current status of $\mathrm{SO}_{2}$ emissions. Considering these factors in the variation of $\mathrm{NO}_{x}$ and $\mathrm{SO}_{2}$ emissions over China and Japan, it was assumed that the 2008 emissions would be within the range of uncertainty of the bottom-up emission inventories. Because REAS does not consider the monthly variation in $\mathrm{NH}_{3}$, we used the monthly variation estimated by Huang et al. (2012). The annual $\mathrm{NH}_{3}$ emission amount was also adjusted to match the estimate of Huang et al. (2012). Other anthropogenic emissions, such as BC, organic carbon (OC), and volatile organic compounds (VOC), were also assumed to be at the 2008 level due to the lack of information needed to update the status. The anthropogenic emission amounts of $\mathrm{SO}_{2}, \mathrm{NO}_{x}$, and $\mathrm{NH}_{3}$ in January 2015 are listed in Table 1. the biogenic emissions were prepared from the Model of Emissions of Gases and Aerosols from Nature (MEGAN; Guenther et al., 2012). As a biogenic source, dimethylsulfide (DMS) was not treated in the modeling system. The biomass burning emissions were used from the climatological database of REanalysis of the TROpospheric chemical composition (RETRO; Schultz et al., 2008). The volcanic activity data were taken from the Ace-Asia and TRACE-P Modeling and Emission Support System (ACESS; Streets et al., 2003) and were modified by the volcanic activity observation data from the Japan Meteorological Agency (JMA) for available volcanoes (JMA, 2016). The 14 main active volcanoes in Japan, along with and Mount Mayon and Mount Bulusan on the island of Luzon in the Philippines, were considered. The model simulation using the above dataset is referred to as the base case simulation. The modeling system domain with overlaid anthropogenic $\mathrm{NO}_{x}$ emissions is shown in Fig. 3.

To investigate whether the effect of domestic or transboundary air pollution is dominant, we also conducted a sensitivity simulation in which the anthropogenic emissions in Japan are switched off. Here, the anthropogenic emissions were taken from the REAS inventory; because of this, emis-

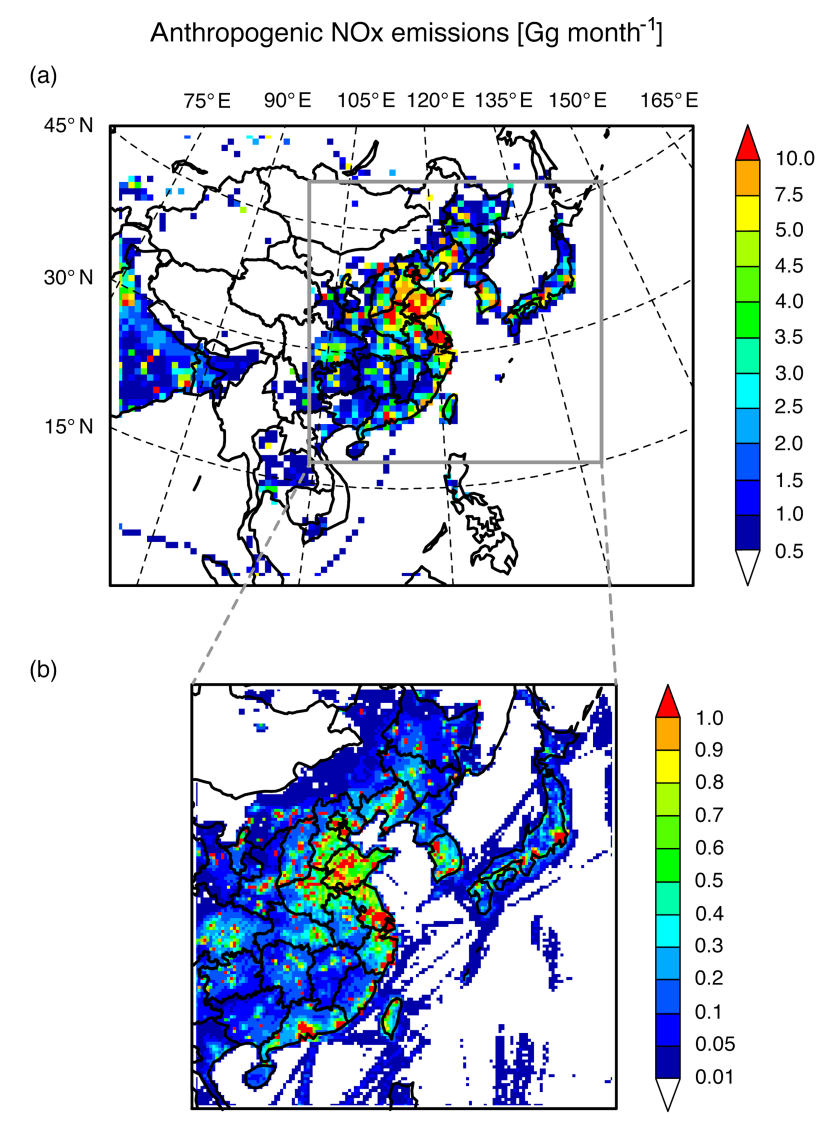

Figure 3. The modeling domain for the horizontal resolutions of (a) $81 \mathrm{~km}$ and (b) $27 \mathrm{~km}$ with anthropogenic $\mathrm{NO}_{x}$ emissions.

sions from agriculture were included. Shipping emissions were not treated in the sensitivity simulation. In terms of $\mathrm{O}_{3}$, which is involved in complex nonlinear chemistry, larger nonlinearities in the atmospheric concentration response to emission variation for China, but not Japan, were clarified due to the higher amount of emissions from China than from Japan (Itahashi et al., 2015). Therefore, the sensitivity simulation was designed to remove the anthropogenic emissions in Japan instead of those in China. Based on the differences between the base case simulation and this sensitivity simulation, the domestic contribution from Japan was estimated.

\section{Results and discussion}

\subsection{Meteorological conditions}

The meteorological conditions during the intensive observation campaign from 7-17 January 2015 are shown in Fig. 4 with the observations and model results. The meteorological observation stations of the JMA in the corresponding nested model grid of Fukuoka were used. Temperatures (Fig. 4a) were around $5{ }^{\circ} \mathrm{C}$ at night and $10^{\circ} \mathrm{C}$ during the day in January 2015 . On 9 January, the temperature was nearly $0^{\circ} \mathrm{C}$ at 
Fukuoka. For the wind field (Fig. 4b and c), because of the dominance of the northwesterly wind system from the Asian continent in winter, the wind direction was generally 270 $360^{\circ}$ (west to north) and the wind speed was around $5 \mathrm{~m} \mathrm{~s}^{-1}$, with the exception of 9 and 12-15 January. On 9 January when the coldest temperature during the intensive observation campaign was observed, the wind speed was less than $1 \mathrm{~m} \mathrm{~s}^{-1}$ and the wind direction was from the south. From 13-15 January, the wind speed was also low at $2-3 \mathrm{~m} \mathrm{~s}^{-1}$, and the wind direction was easterly, caused by a warm front passing over the south of Kyushu on 14 January. After the warm front had passed, the relative humidity was close to $100 \%$ on 15-16 January (Fig. 4d) with maximum rainfall of $10 \mathrm{~mm} \mathrm{~h}^{-1}$ on 15 January (Fig. 4e). The model tended to underestimate the precipitation amount, as we have reported in a previous study (Itahashi et al., 2014). Comparing the observations with the model results shows that our modeling system generally captures the observed meteorological variations during this episode.

\subsection{Temporal variation of particulate matter}

\subsection{1 $\mathrm{PM}_{2.5}$}

The temporal variation in $\mathrm{PM}_{2.5}$ over Japan at Fukuoka, Tsushima Island, the Goto Islands, and Tottori are presented in Fig. 1. The $\mathrm{PM}_{2.5}$ observation data are taken from the ACSA at Fukuoka and from the PM-712 at other sites. The temporal resolution is $1 \mathrm{~h}$ for all observations. During the analyzed period of 7-17 January 2015, episodic $\mathrm{PM}_{2.5}$ peaks reached around $100 \mu \mathrm{g} \mathrm{m}^{-3}$ at Fukuoka twice. The first peak, observed at 12:00 LT on 11 January (shown in blue in Fig. 1), reached a maximum concentration of $86.4 \mu \mathrm{g} \mathrm{m}^{-3}$ at Fukuoka and $105.1 \mathrm{\mu g} \mathrm{m}^{-3}$ at the Goto Islands. During this first peak, the concentration at Tsushima Island was $63.9 \mu \mathrm{g} \mathrm{m}^{-3}$, which was lower than at the other remote island sites in the Goto Islands, and there was no distinctive peak at Tottori. The second peak, observed at 00:00 LT on 17 January (shown in red in Fig. 1), reached a maximum concentration at Fukuoka of $106.2 \mu \mathrm{g} \mathrm{m}^{-3}$. During this second peak, the remote sites of the Goto Islands and Tsushima Island also recorded high $\mathrm{PM}_{2.5}$ concentrations of 104.8 and $89.1 \mu \mathrm{g} \mathrm{m}^{-3}$, respectively, and the $\mathrm{PM}_{2.5}$ concentration reached $37.6 \mu \mathrm{g} \mathrm{m}^{-3}$ at Tottori. In Fig. 1, we show the model results as black lines. Generally, the model captured the observed temporal $\mathrm{PM}_{2.5}$ behavior, although it underestimated the first peaks at Fukuoka and the Goto Islands and the second peak at the Goto Islands. The timing of the high $\mathrm{PM}_{2.5}$ concentration was reproduced well by the modeling system. A statistical analysis of the model reproducibility demonstrated that all paired datasets for $\mathrm{PM}_{2.5}$ showed good correlations between the observations and the model at the four sites in Japan, with a correlation coefficient $(R)$ of 0.86 . The mean fractional bias (MFB) and mean fractional error (MFE) were -42.6 and $67.4 \%$, respectively,

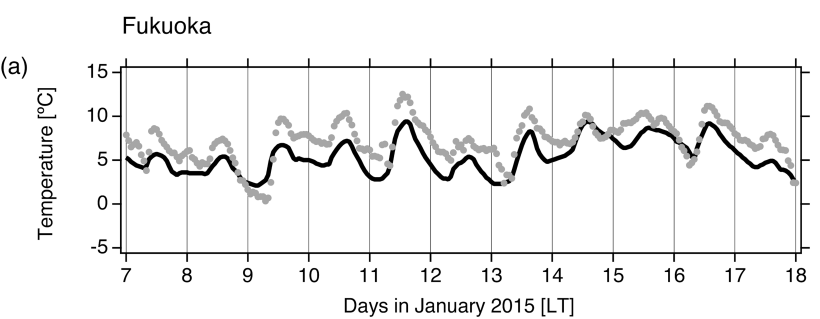

(b)

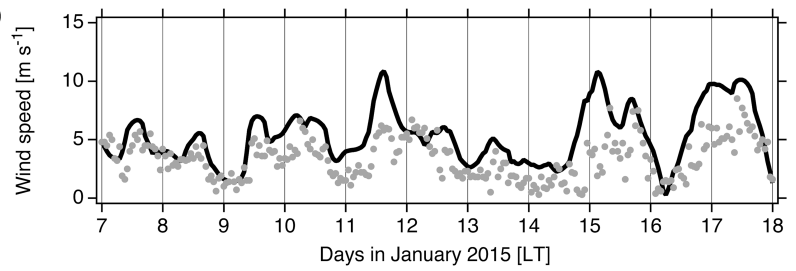

(c)

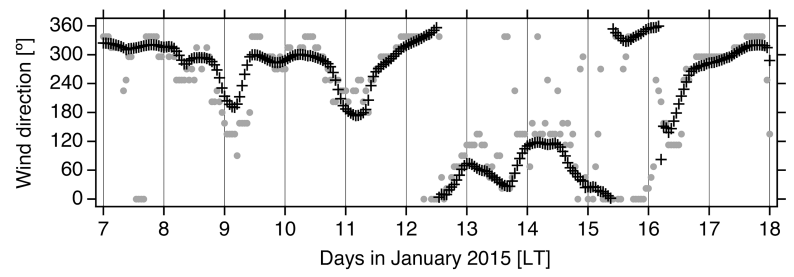

(d)

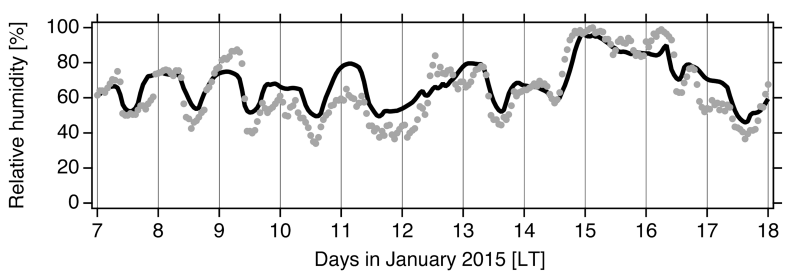

(e)

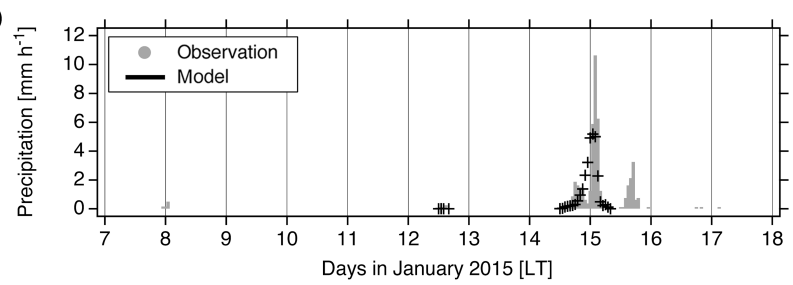

Figure 4. The temporal variation in (a) temperature, (b) wind speed, (c) wind direction, (d) relative humidity, and (e) precipitation at Fukuoka from 7-17 January 2015. The gray and black coloring indicates the observations and the model results, respectively.

and these results satisfied the model performance criteria (MFB $\leq \pm 60 \%$ and MFE $\leq+75 \%$ ) proposed by Boylan and Russell (2006). Figure 1 also shows the model results of a sensitivity simulation performed by switching off the Japanese anthropogenic emissions. The sensitivity simulation results are shown as dotted black lines, and the difference between the base case and the sensitivity simulation is shown in gray, which indicates the domestic contribution of Japan. Except for Fukuoka, there were few domestic contributions for $\mathrm{PM}_{2.5}$; therefore, transboundary air pollution was dominant in January 2015 at remote sites in western Japan. At Fukuoka, although domestic contributions for $\mathrm{PM}_{2.5}$ were found in some cases (from 8-10 and on 14 January), the 
concentration of $\mathrm{PM}_{2.5}$ was lower compared with the two peaks. During the two episodes when $\mathrm{PM}_{2.5}$ concentration reached around $100 \mu \mathrm{g} \mathrm{m}^{-3}$ over Japan, the model simulation suggested that the effect of transboundary air pollution was dominant, even at Fukuoka.

The temporal variations in $\mathrm{PM}_{2.5}$ over China at Beijing, Shanghai, and Shenyang are shown in Fig. 2. The $\mathrm{PM}_{2.5}$ observation data are taken from the BAMs, and the temporal resolution is $1 \mathrm{~h}$. The model results of a sensitivity simulation suggested that the impact on three Chinese sites from Japanese anthropogenic emissions was negligible during this period. At Beijing, there were high concentrations of $\mathrm{PM}_{2.5}$ that correspond to the high concentration of $\mathrm{PM}_{2.5}$ found over Japan. One high concentration was approximately $300 \mu \mathrm{g} \mathrm{m}^{-3}$ on 10-11 January and another was around $600 \mu \mathrm{g} \mathrm{m}^{-3}$ on 16 January. These peak times were almost 1 day before the high concentration was observed over Japan. At Shanghai, there were two clear peaks with a $\mathrm{PM}_{2.5}$ concentration of $200 \mu \mathrm{g} \mathrm{m}^{-3}$ on 11 and 17 January. The time corresponded well to the peak time over Japan. At Shenyang, where the local emissions from domestic sources were dominant in winter, the temporal variation was complex compared with Beijing and Shanghai. $\mathrm{PM}_{2.5}$ showed sharp peaks several times with concentrations of around $300 \mu \mathrm{g} \mathrm{m}^{-3}$, whereas the model only showed gentle peaks. An analysis of the model reproducibility showed that all for $\mathrm{PM}_{2.5}$ paired datasets for the observations and the model at three sites over China, $R$ was 0.73 and MFB and MFE were -9.8 and $46.8 \%$, respectively; these numbers satisfy the model goal criteria (MFB $\leq \pm 30 \%$ and MFE $\leq \pm 50 \%$ ) proposed by Boylan and Russell (2006). The evaluation of the model performance over China supports the discussion on downwind regions.

\subsubsection{SNA}

The temporal variations in SNA are shown in Figs. 5 and 6. In Fig. 5, $\mathrm{SO}_{4}^{2-}$ and $\mathrm{NH}_{4}^{+}$are shown for four sites in Japan. At Fukuoka, the ACSA and D-F pack observations are shown for $\mathrm{SO}_{4}^{2-}$. The $\mathrm{NH}_{x}$ monitor and D-F pack results are shown for $\mathrm{NH}_{4}^{+}$. The temporal resolutions of the ACSA and the $\mathrm{NH}_{x}$ monitor were $1 \mathrm{~h}$, and those of the D$\mathrm{F}$ packs were 6-8 $\mathrm{h}$ depending on the samples. For the Goto Islands, Tsushima Island, and Tottori, the PM-712 tape filter data were used. The temporal resolution was $4 \mathrm{~h}$ at the Goto Islands and Tsushima Island and 1 or 0.5 days at Tottori. In Fig. 6, $\mathrm{NO}_{3}^{-}, \mathrm{HNO}_{3}, \mathrm{NH}_{3}$, and total ammonia (sum of $\mathrm{NH}_{4}^{+}$ and $\mathrm{NH}_{3}$ ) are shown for Fukuoka. The ACSA and D-F pack observations for $\mathrm{NO}_{3}^{-}$are shown, the D-F pack observations are shown for $\mathrm{HNO}_{3}$, and the $\mathrm{NH}_{x}$ monitor observations are shown for $\mathrm{NH}_{3}$ and total ammonia. Because of a temperature change during the PM-712 sample storage, the $\mathrm{NO}_{3}^{-}$concentrations could have been affected by volatilization; hence, only the $\mathrm{NO}_{3}^{-}$analysis at the Fukuoka site was used. At Fukuoka, the SNA concentration contributed 52 and $46 \%$ of the $\mathrm{PM}_{2.5}$ concentration in the first and second episodes, respectively. For $\mathrm{SO}_{4}^{2-}$ (Fig. 5; left), the concentration during the second episode was larger than during the first episode at Fukuoka, the Goto Islands, and Tsushima Island. At Tottori, there was no peak for the first episode for $\mathrm{SO}_{4}^{2-}$. In contrast to $\mathrm{SO}_{4}^{2-}$, a higher $\mathrm{NO}_{3}^{-}$concentration was observed during the first episode instead of the second episode (Fig. 6). $\mathrm{NH}_{4}^{+}$ showed high concentrations during both episodes because it is the counterion for $\mathrm{SO}_{4}^{2-}$ and $\mathrm{NO}_{3}^{-}$(Fig. 5; right). Based on the analysis of the $\mathrm{PM}_{2.5}$ (Fig. 1) and SNA (Figs. 5 and 6) observations, the $\mathrm{PM}_{2.5}$ concentrations were similar during the episodes on 11 and 17 January; however, the main component of SNA was $\mathrm{NO}_{3}^{-}$during the first episode and $\mathrm{SO}_{4}^{2-}$ during the second episode. At Fukuoka, the relative portions of $\mathrm{SO}_{4}^{2-}, \mathrm{NO}_{3}^{-}$, and $\mathrm{NH}_{4}^{+}$within the $\mathrm{PM}_{2.5}$ were respectively 18,20 , and $14 \%$ during the first episode, and 27 , 6 , and $14 \%$ during the second episode. Therefore, the first episode (shown in blue in Figs. 1, 5, 6, 7 and 8) is referred to as "type N", and the second episode (shown in red in Figs. 1, $5,6,7$ and 8) is referred to as "type $S$ " hereafter.

The model results for the base case and sensitivity simulations are overlaid with the same temporal resolution as the observations in Figs. 5 and 6. The model tended to underestimate the $\mathrm{SO}_{4}^{2-}$ concentration (Fig. 5; left); however, the model reproduced the features of types $\mathrm{N}$ and $\mathrm{S}$, and the sensitivity simulation indicated the dominance of transboundary air pollution for $\mathrm{SO}_{4}^{2-}$ during the intensive observation campaign in January 2015, even at Fukuoka. For $\mathrm{NO}_{3}^{-}$(Fig. 6), the model reproduced the features of the type $\mathrm{N}$ and $\mathrm{S}$ peaks well, although the model overestimated the dip in $\mathrm{NO}_{3}^{-}$concentration found from the evening of 10 January to before the type $\mathrm{N}$ episode. The $\mathrm{D}-\mathrm{F}$ pack observations generally underestimated $\mathrm{NO}_{3}^{-}$compared with the ACSA observations because of the difference in the cutoff diameter between these measurement systems. Except for the type $\mathrm{N}$ and $\mathrm{S}$ episodes, domestic contributions were seen for $\mathrm{NO}_{3}^{-}$from 8-10 and on 14 January. However, the sensitivity simulation confirmed that transboundary $\mathrm{NO}_{3}^{-}$air pollution was dominant for types $\mathrm{N}$ and $\mathrm{S}$. Because $\mathrm{NH}_{4}^{+}$is the counterion for both $\mathrm{SO}_{4}^{2-}$ and $\mathrm{NO}_{3}^{-}$, small domestic contributions for $\mathrm{NH}_{4}^{+}$were observed at Fukuoka (Fig. 5; right). This result corresponded to the domestic contribution for $\mathrm{NO}_{3}^{-}$. For the other three remote sites, there were no domestic contributions for $\mathrm{NH}_{4}^{+}$.

The behavior of SNA, gas-phase $\mathrm{HNO}_{3}$, and $\mathrm{NH}_{3}$ was analyzed comprehensively based on the $\mathrm{NH}_{x}$ monitor and D-F pack observations (Fig. 6) to support our understanding of $\mathrm{NO}_{3}^{-}$behavior. There are few synergetic analyses including gas-phase behavior over the downwind region of the Asian continent. Peaks for gas-phase $\mathrm{HNO}_{3}$ were found for types $\mathrm{N}$ and $\mathrm{S}$, whereas the concentration of gas-phase $\mathrm{NH}_{3}$ was nearly zero (less than $1 \mu \mathrm{g} \mathrm{m}^{-3}$ for $24 \mathrm{~h}$ average) for types $\mathrm{N}$ and $\mathrm{S}$ on $8,10,12$, and 15 January (the green arrows in Fig. 6). Type S, in particular, showed an almost zero concentration of $\mathrm{NH}_{3}$. The concentration of total am- 

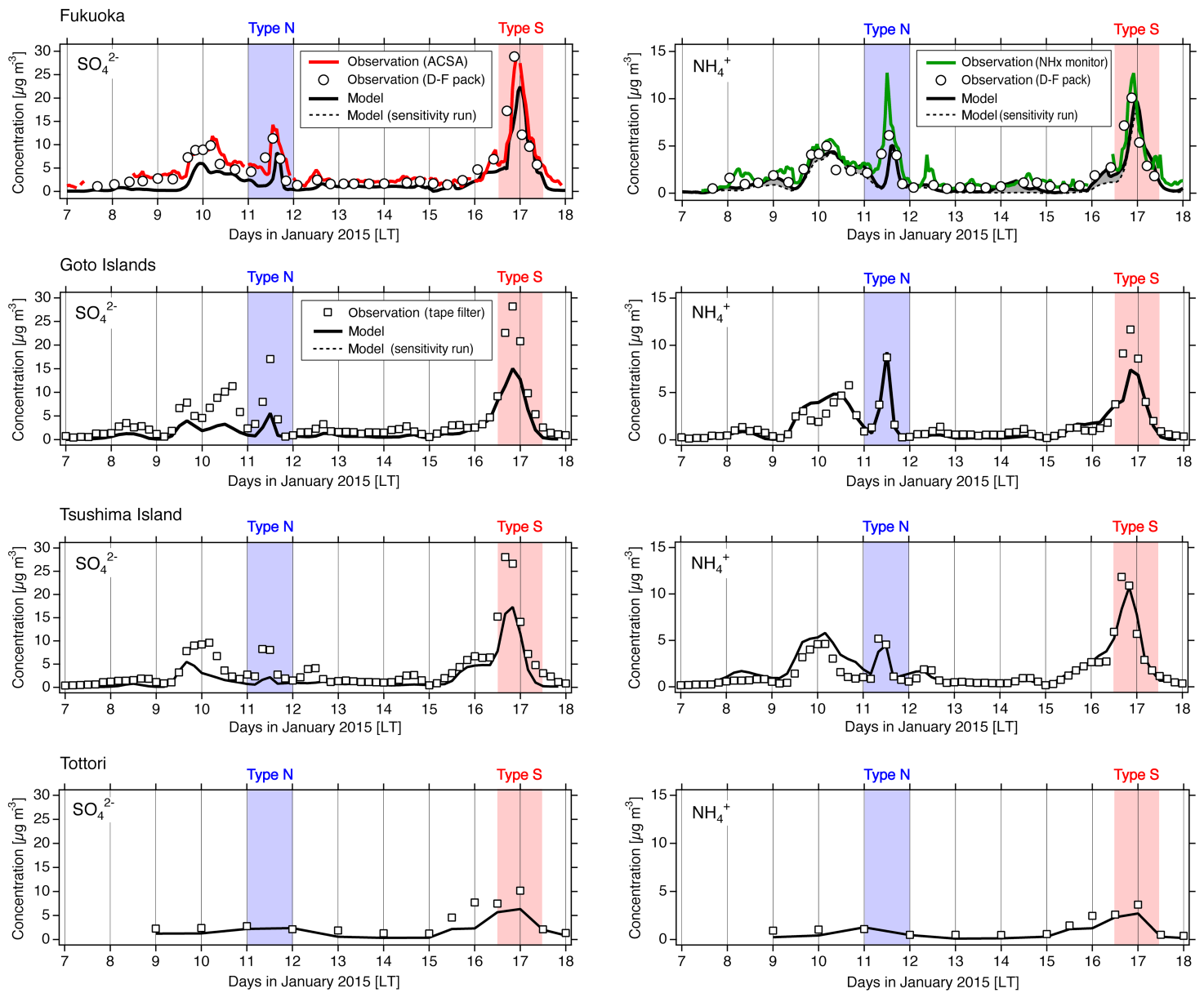

Figure 5. The temporal variation in $\mathrm{SO}_{4}^{2-}$ and $\mathrm{NH}_{4}^{+}$over Japan at Fukuoka, the Goto Islands, Tsushima Island, and Tottori from 7-17 January 2015. The blue and red shading shows the type $\mathrm{N}$ and $\mathrm{S}$ patterns focused on in this study. The red lines indicate $\mathrm{SO}_{4}^{2-}$ observations by ACSA, and the green lines indicate $\mathrm{NH}_{4}^{+}$observations by the $\mathrm{NH}_{x}$ monitor at Fukuoka. The open circles are D-F pack observations at Fukuoka. The open squares are tape filter measurements at the Goto Islands, Tsushima Island, and Tottori. The black lines indicate the base case simulation, and the dotted black lines indicate the sensitivity simulation in which the anthropogenic emissions from Japan were switched off; the differences between these results, shown in gray, represent local contributions.

monia showed distinct peaks for types $\mathrm{N}$ and $\mathrm{S}$; therefore, the nearly zero concentration of $\mathrm{NH}_{3}$ suggested the full conversion of $\mathrm{NH}_{3}$ to produce $\mathrm{NH}_{4}^{+}$as a counterion for $\mathrm{SO}_{4}^{2-}$ and $\mathrm{NO}_{3}^{-}$. The sensitivity simulation, in which Japanese anthropogenic emissions were switched off, clarified the different features of related gas-phase species. The base case simulation and sensitivity simulation were similar for $\mathrm{HNO}_{3}$, suggesting that it originated from transboundary air pollution. A slight increase in $\mathrm{HNO}_{3}$ in the sensitivity simulation was found from 8-10 and on 12 January (the red arrows in Fig. 6). These were the complex cases connected to overseas and domestic emissions. If there are no Japanese $\mathrm{NH}_{3}$ emissions, the transported $\mathrm{HNO}_{3}$ cannot produce $\mathrm{NO}_{3}^{-}$in Japan, and so it remains as gas-phase $\mathrm{HNO}_{3}$. The synergetic analysis for gas-phase $\mathrm{HNO}_{3}$ and $\mathrm{NH}_{3}$ indicated that abundant $\mathrm{HNO}_{3}$ was transported from abroad and reacted with do- mestic $\mathrm{NH}_{3}$, producing $\mathrm{NO}_{3}^{-}$from 8-10 January. Compared with these cases, domestic $\mathrm{HNO}_{3}$ and $\mathrm{NH}_{3}$ produced $\mathrm{NO}_{3}^{-}$ on 14 January (orange arrows in Fig. 6). The concentrations were lower than for types $\mathrm{N}$ and $\mathrm{S}$, which were dominated by transboundary air pollution.

\subsubsection{Coarse-mode aerosols}

Coarse-mode aerosols were also partly analyzed in this study. Because of the effect of transboundary air pollution on $\mathrm{HNO}_{3}$ (Fig. 6), we focused on coarse-mode $\mathrm{NO}_{3}^{-}$. Coarse-mode $\mathrm{NO}_{3}^{-}$is produced by reactions of $\mathrm{HNO}_{3}$ with mineral dust or sea salt particles. In general, mineral dust mainly has an effect in spring over East Asia (Itahashi et al., 2010), whereas sea salt particles play an important role throughout the year. Recently, we reported the importance of coarse-mode $\mathrm{NO}_{3}^{-}$ 

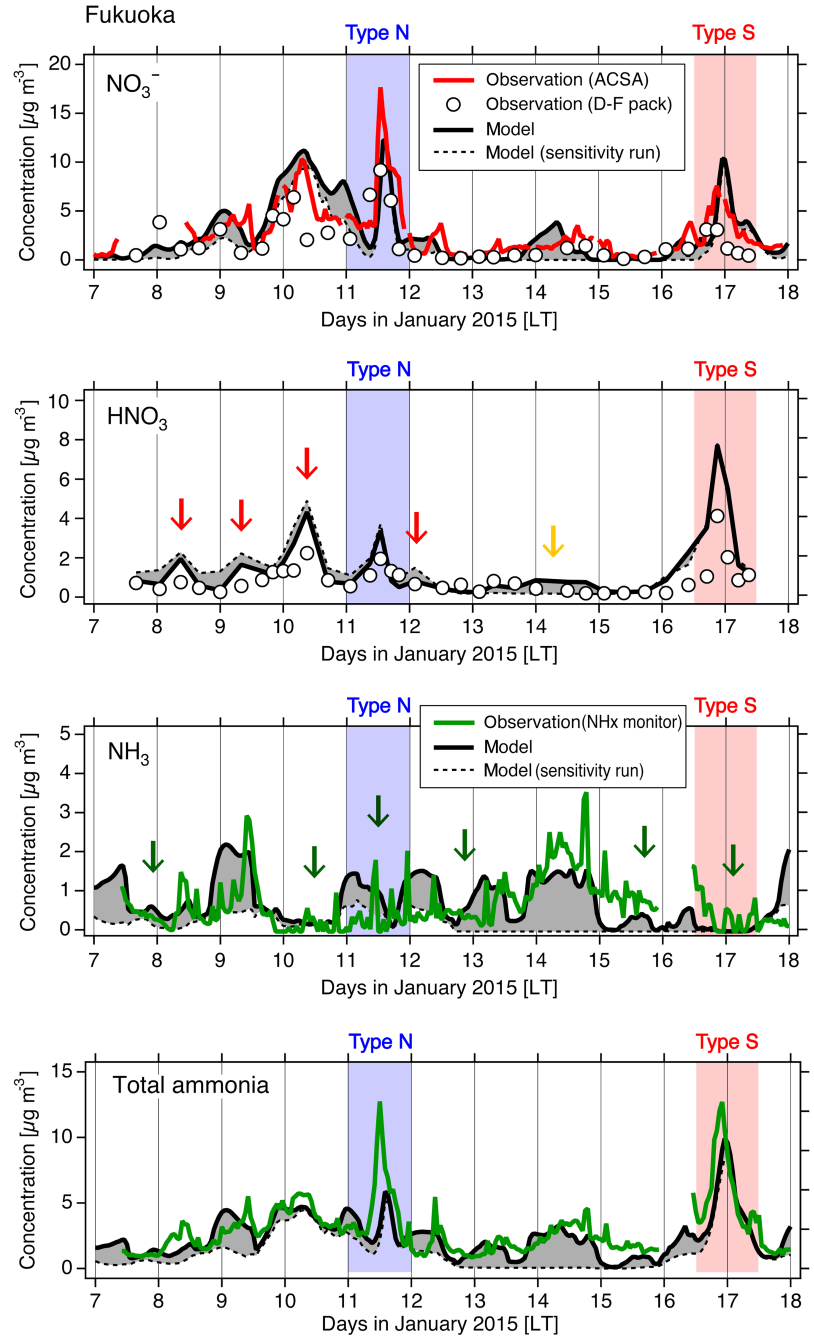

Figure 6. The temporal variation in $\mathrm{NO}_{3}^{-}, \mathrm{HNO}_{3}, \mathrm{NH}_{3}$, and total ammonia at Fukuoka from 7-17 January 2015. The blue and red shading shows the type $\mathrm{N}$ and $\mathrm{S}$ patterns focused on in this study. The red lines indicate $\mathrm{NO}_{3}^{-}$observations by the ACSA, the green lines indicate $\mathrm{NH}_{3}$ and total ammonia observations by the $\mathrm{NH}_{x}$ monitor, and the open circles indicate D-F pack observations. For $\mathrm{NH}_{3}$, periods of nearly zero concentration ( $24 \mathrm{~h}$ average of less than $1 \mu \mathrm{g} \mathrm{m}^{-3}$ ) are indicated by arrows. The black lines indicate the base case simulation, and the dotted black lines indicate the sensitivity simulation in which the anthropogenic emissions from Japan were switched off; the differences between these results, shown in gray, represent local contributions.

as an atmospheric input in East Asian ocean regions (Itahashi et al., 2016). Figure 7 shows the modeled and observed coarse-mode $\mathrm{NO}_{3}^{-}, \mathrm{Na}^{+}$, and $\mathrm{Cl}^{-}$. The ACSA and D-F pack observations are shown for coarse-mode $\mathrm{NO}_{3}^{-}$, and the $\mathrm{D}-\mathrm{F}$ pack observations are shown for coarse-mode $\mathrm{Na}^{+}$and $\mathrm{Cl}^{-}$. During the intensive observation period in January, coarsemode $\mathrm{NO}_{3}^{-}$also showed high concentrations for types $\mathrm{N}$ and $\mathrm{S}$ of around $10 \mu \mathrm{g} \mathrm{m}^{-3}$ (on 9-10 January, around $5 \mu \mathrm{g} \mathrm{m}^{-3}$ ).
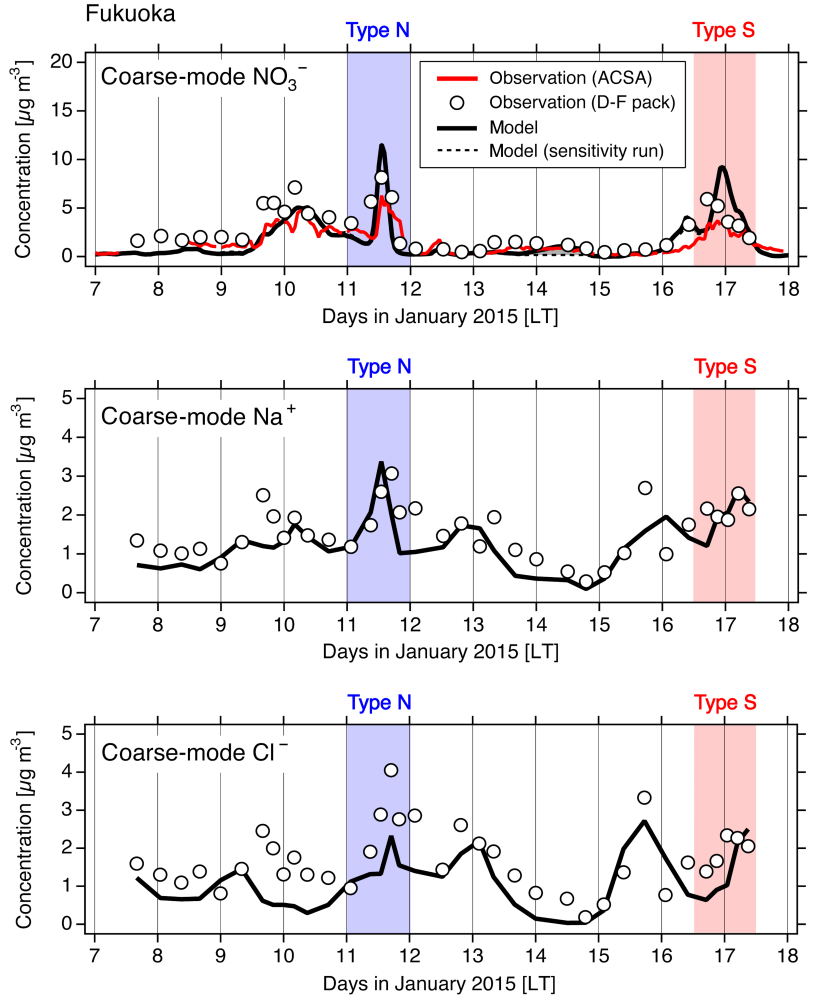

Figure 7. The temporal variation in coarse-mode $\mathrm{NO}_{3}^{-}, \mathrm{Na}^{+}$, and $\mathrm{Cl}^{-}$at Fukuoka from 7-17 January 2015. The blue and red shading shows the type $\mathrm{N}$ and $\mathrm{S}$ patterns focused on in this study. The red lines indicate coarse-mode $\mathrm{NO}_{3}^{-}$observations by the ACSA, and the open circles indicate D-F pack observations. The black lines indicate the base case simulation, and the dotted black lines indicate the sensitivity simulation in which the anthropogenic emissions from Japan were switched off; the differences between these results, shown in gray, represent local contributions.

Based on the model results and because the domestic contribution for $\mathrm{HNO}_{3}$ was found on 14 January (Fig. 6), the domestic contribution for coarse-mode $\mathrm{NO}_{3}^{-}$was found only on 14 January, but the concentration was below $1 \mu \mathrm{g} \mathrm{m}^{-3}$. $\mathrm{Na}^{+}$and $\mathrm{Cl}^{-}$from sea salt particles also had peaks for types $\mathrm{N}$ and S. Sea salt particles are mechanically produced by high winds; therefore, these peaks generally corresponded to high wind speeds (Fig. 4b). High winds were observed on 15 January; $\mathrm{Na}^{+}$and $\mathrm{Cl}^{-}$peaks occurred, but the coarse-mode $\mathrm{NO}_{3}^{-}$concentration was close to zero. This was because there was no $\mathrm{HNO}_{3}$ to react with $\mathrm{NaCl}$ from 12-15 January or the wet deposition of coarse-mode $\mathrm{NO}_{3}^{-}$with the precipitation from noon on 14 January to the evening of 15 January. For coarse-mode $\mathrm{NO}_{3}^{-}$, transboundary air pollution was the dominant factor. This means that a large amount of $\mathrm{HNO}_{3}$ was transported from abroad (Fig. 6), reacted with sea salt particles over the ocean, and reached Fukuoka in the air mass. 


\subsubsection{BC}

To support the discussion of the domestic and transboundary contributions to SNA, the behavior of BC at Fukuoka and the Goto Islands is shown in Fig. 8. The sensitivity simulation would suffer from a nonlinear chemical response if complex atmospheric chemistry were involved; hence, we focused on $\mathrm{BC}$, which is a primary aerosol. The temporal variation of $\mathrm{BC}$ also showed distinctive peaks for types $\mathrm{N}$ and $\mathrm{S}$ at Fukuoka and the Goto Islands. The model results reproduced these peaks well, and the sensitivity simulation also suggested the dominance of transboundary air pollution for both peaks $\mathrm{N}$ and $\mathrm{S}$. The temporal variation at the Goto Islands showed only two peaks of types $\mathrm{N}$ and $\mathrm{S}$, although many short-term peaks were seen at Fukuoka. The sensitivity simulation confirmed that domestic air pollution contributed to these shortterm peaks at Fukuoka; however, the model could not fully capture the peaks observed on 7, 13, and 14 January. To improve the performance of the model to capture these shortterm peaks, a higher resolution model simulation and a revision of the emission inventory are needed. An analysis of the primary aerosol confirmed that transboundary air pollution was dominant for types $\mathrm{N}$ and $\mathrm{S}$ in January 2015.

Consequently, the well-validated model simulation indicated that two high $\mathrm{PM}_{2.5}$ episodes with concentrations of around $100 \mu \mathrm{g} \mathrm{m}^{-3}$ occurring over western Japan in January were dominated by $\mathrm{NO}_{3}^{-}$for the first peak (type $\mathrm{N}$ ) and by $\mathrm{SO}_{4}^{2-}$ for the second peak (type $\mathrm{S}$ ); the $\mathrm{NH}_{4}^{+}$concentration was high for both types. The model sensitivity simulation clarified that these high SNA concentrations in the type N and $\mathrm{S}$ episodes were dominated by transboundary air pollution. In addition to the transport of SNA, abundant gas-phase $\mathrm{HNO}_{3}$ and coarse-mode $\mathrm{NO}_{3}^{-}$reacted with sea salt particles over the ocean and were also transported to western Japan. $\mathrm{NH}_{3}$, which mainly came from domestic emissions, showed concentrations of around zero during type $\mathrm{N}$ and $\mathrm{S}$ events, suggesting that $\mathrm{NH}_{3}$ was depleted to neutralize $\mathrm{SO}_{4}^{2-}$ and $\mathrm{NO}_{3}^{-}$.

\subsection{Trajectory analysis}

Analyzing the synergetic observations at Fukuoka and the other three remote sites in Japan with the regional chemical transport model demonstrated that the two $\mathrm{PM}_{2.5}$ episodic peaks were dominated by transboundary heavy pollution, even at Fukuoka. The two peaks had different SNA compositions. The first episode on 11 January showed a high $\mathrm{NO}_{3}^{-}$(type $\mathrm{N}$ ) concentration and the second episode on 17 January was dominated by $\mathrm{SO}_{4}^{2-}$ (type $\mathrm{S}$ ). The differences in these episodes were investigated further by a model simulation combined with a backward trajectory analysis. The spatial distributions of $\mathrm{SO}_{4}^{2-}$ and $\mathrm{NO}_{3}^{-}$during type $\mathrm{N}$ and $\mathrm{S}$ patterns are shown in Figs. 9 and 10, respectively.

In type $\mathrm{N}$ (Fig. 9; right), the model results showed that a low $\mathrm{SO}_{4}^{2-}$ concentration of less than $5 \mu \mathrm{g} \mathrm{m}^{-3}$ and a
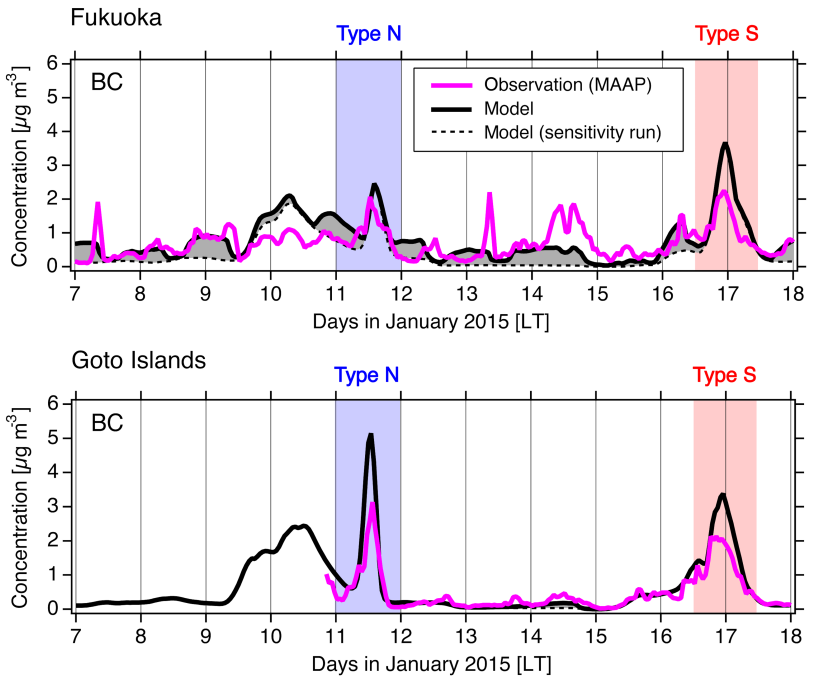

Figure 8. The temporal variation in $\mathrm{BC}$ at Fukuoka and the Goto Islands from 7-17 January 2015. The blue and red shading shows the type $\mathrm{N}$ and $\mathrm{S}$ patterns focused on in this study. The magenta line indicates BC observations by MAAP. The black lines indicate the base case simulation, and the dotted black lines indicate the sensitivity simulation in which the anthropogenic emissions from Japan were switched off; the differences between these results, shown in gray, represent local contributions.

high $\mathrm{NO}_{3}^{-}$concentration of more than $10 \mu \mathrm{g} \mathrm{m}^{-3}$ covered Fukuoka. The spatial distribution patterns indicated an outflow of $\mathrm{SO}_{4}^{2-}$ and $\mathrm{NO}_{3}^{-}$from continental Asia to western Japan. The dominance of transboundary air pollution suggested by these spatial distributions was consistent with the model sensitivity simulation results (Figs. 5 and 6). Highconcentration regions of $\mathrm{SO}_{4}^{2-}$ and $\mathrm{NO}_{3}^{-}$stretched from the eastern coastline of China to the East China Sea and western Japan. The spatial distribution implied the direct transport from continental Asia to the downwind regions. In addition, the high-concentration region stretched from eastern China to western Japan, which is consistent with the corresponding $\mathrm{PM}_{2.5}$ peak on 11 January at Shanghai and over Japan. To investigate the air mass origin for type $\mathrm{N}$, the HYSPLIT backward trajectory (Stein et al., 2015) was analyzed over $72 \mathrm{~h}$ starting from Fukuoka ( $T_{\mathrm{N}}$ in Fig. 9; left). The backward trajectory during type $\mathrm{N}$ transport suggested that the air mass originated from Shaanxi Province and passed over Shanxi Province, southern Hebei Province, and Shandong Province, and then reached Fukuoka. The traveling time from the coast of China to Fukuoka was about $18 \mathrm{~h}$. The distance from the coastline of China to Fukuoka is approximately $1000 \mathrm{~km}$, so the air mass speed for type $\mathrm{N}$ was $55.6 \mathrm{~km} \mathrm{~h}^{-1}$. Figure 9 (left) shows the spatial distribution when the air mass was located over China. A high concentration of $\mathrm{NO}_{3}^{-}$of more than $60 \mu \mathrm{g} \mathrm{m}^{-3}$ occurred over the east coast of China before the air mass arrived in Fukuoka, whereas the $\mathrm{SO}_{4}^{2-}$ concentration was as high as $10 \mu \mathrm{g} \mathrm{m}^{-3}$ above the East China Sea. 
Type $\mathrm{N}$

21:00 LT, 10 January 2015

(a) $\mathrm{SO}_{4}^{2-}$

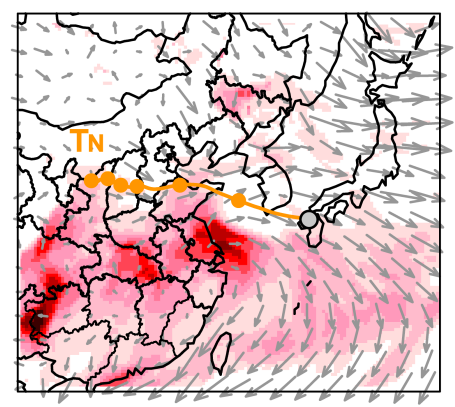

(b) $\mathrm{NO}_{3}$

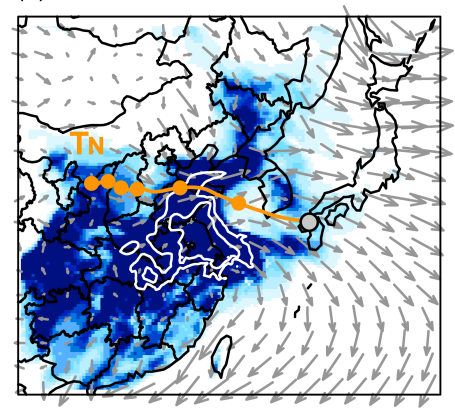

15:00 LT, 11 January 2015
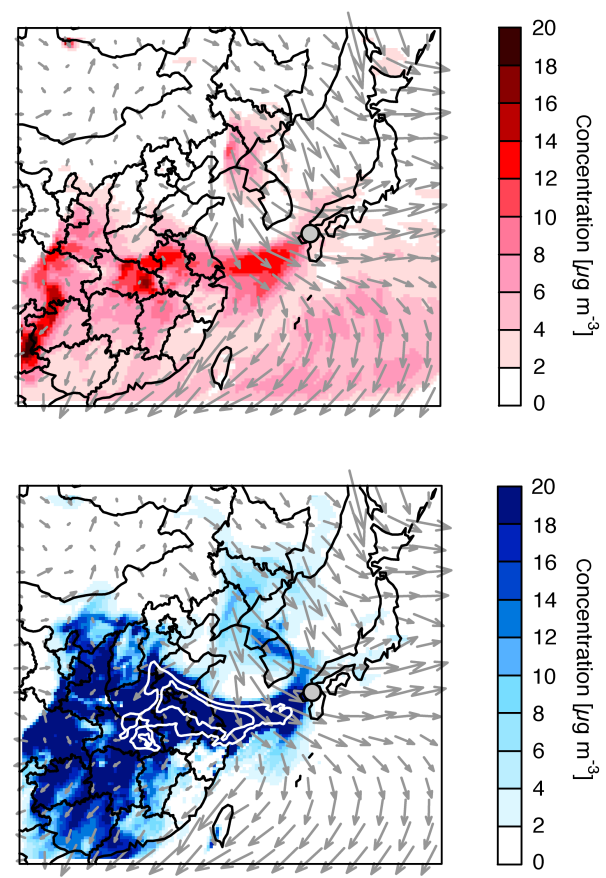

$15\left[\mathrm{~m} \mathrm{~s}^{-1}\right.$

Figure 9. The simulated spatial distribution of (a) $\mathrm{SO}_{4}^{2-}$ and (b) $\mathrm{NO}_{3}^{-}$during a type $\mathrm{N}$ pattern. The contours shown by the white lines for $\mathrm{NO}_{3}^{-}$represent 40 and $60 \mu \mathrm{g} \mathrm{m}{ }^{-3}$. The $72 \mathrm{~h}$ HYSPLIT backward trajectory from Fukuoka is overlaid with orange lines and orange circles at $12 \mathrm{~h}$ intervals. (Left) 21:00 LT on 10 January 2015 when the air mass left China and (right) 15:00 LT on 11 January 2015 when the air mass reached Fukuoka.

In type $\mathrm{S}$ (Fig. 10; right), the model calculated that a high $\mathrm{SO}_{4}^{2-}$ concentration of more than $20 \mu \mathrm{g} \mathrm{m}^{-3}$ and a low $\mathrm{NO}_{3}^{-}$concentration of around $5 \mu \mathrm{g} \mathrm{m}^{-3}$ covered Fukuoka. The HYSPLIT backward trajectory is shown as $T_{\mathrm{S}}$ in Fig. 10. The air mass during type $\mathrm{S}$ transport originated from Shanxi Province and slowly moved over northern Henan Province and Shandong Province, and reached Fukuoka within about $24 \mathrm{~h}$. The high-concentration regions stretched from eastern China to western Japan, which is consistent with the simultaneous $\mathrm{PM}_{2.5}$ peak at Shanghai and over Japan. The air mass was stagnant over China compared with type $\mathrm{N}$ transport. The spatial distribution when the air mass was located over China is shown in Fig. 10 (left). For $\mathrm{SO}_{4}^{2-}$, the concentration was higher when the air mass arrived at Fukuoka compared with that in China, suggesting the fast production of $\mathrm{SO}_{4}^{2-}$ during the transport process. A high concentration of $\mathrm{SO}_{4}^{2-}$ of $20 \mu \mathrm{g} \mathrm{m}^{-3}$ spread over the East China Sea and western Japan. A high $\mathrm{NO}_{3}^{-}$concentration of more than $60 \mu \mathrm{g} \mathrm{m}^{-3}$ occurred over China, similar to type $\mathrm{N}$; however, the $\mathrm{NO}_{3}^{-}$ concentration was immediately reduced during the transport. The high $\mathrm{NO}_{3}^{-}$concentration of more than $10 \mu \mathrm{g} \mathrm{m}^{-3}$ did not reach Fukuoka in this type $\mathrm{S}$ transport. Comparing the spa- tial distribution of the air mass over Fukuoka (Fig. 10; right) and China (Fig. 10; left) showed a 1-day delay in the highconcentration peaks over Japan compared with the peak for Beijing (Figs. 1 and 2).

The backward trajectories for types $\mathrm{N}$ and $\mathrm{S}$ both showed similar transport patterns from China and Fukuoka. However, the spatial distribution patterns demonstrated clear differences between $\mathrm{SO}_{4}^{2-}$ and $\mathrm{NO}_{3}^{-}$distributions for type $\mathrm{N}$ and $\mathrm{S}$ patterns. To discuss the different mechanisms for types $\mathrm{N}$ and $\mathrm{S}$ further, the model results were analyzed along the backward trajectories of $T_{\mathrm{N}}$ and $T_{\mathrm{S}}$. The path analyses are shown in Figs. 11 and 12, along with additional indexes. The conversion ratio of SNA from the gas phase to the aerosol phase is an important indicator. For $\mathrm{SO}_{4}^{2-}$, considering the concentration of the gas-phase species of $\mathrm{SO}_{2}$, the conversion ratio of $F_{\mathrm{S}}$ is defined as follows and calculated based on molar concentrations, shown in square brackets (Khoder, 2002):

$$
F_{s}=\frac{\left[\mathrm{SO}_{4}^{2-}\right]}{\left[\mathrm{SO}_{2}\right]+\left[\mathrm{SO}_{4}^{2-}\right]}\left[\mathrm{mol} \mathrm{mol}^{-1}\right] .
$$


Type S

00:00 LT, 16 January 2015

(a) $\mathrm{SO}_{4}^{2-}$

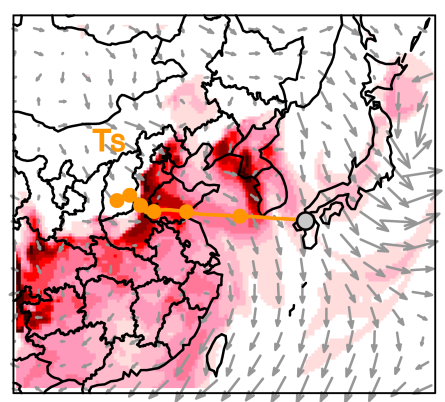

(b) $\mathrm{NO}_{3}-$

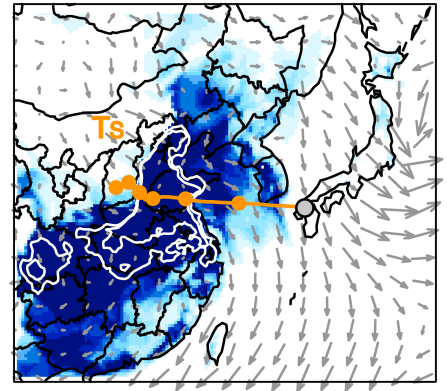

00:00 LT, 17 January 2015
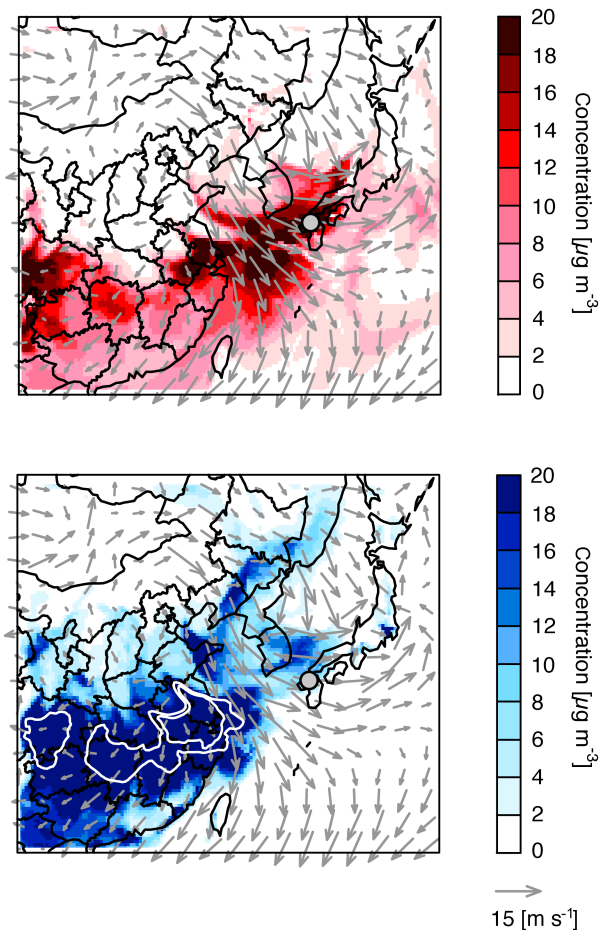

Figure 10. The simulated spatial distribution of (a) $\mathrm{SO}_{4}^{2-}$ and (b) $\mathrm{NO}_{3}^{-}$during a type $\mathrm{S}$ pattern. The contours shown by the white lines for $\mathrm{NO}_{3}^{-}$represent 40 and $60 \mu \mathrm{g} \mathrm{m}^{-3}$. The $72 \mathrm{~h}$ HYSPLIT backward trajectory from Fukuoka is overlaid with orange lines and orange circles at $12 \mathrm{~h}$ intervals. (Left) 00:00 LT on 16 January 2015 when the air mass left China and (right) 00:00 LT on 17 January 2015 when the air mass reached Fukuoka.

A ratio of 0 indicates that $\mathrm{SO}_{4}^{2-}$ was not produced, and a ratio of 1 indicates that $\mathrm{SO}_{2}$ was converted completely to $\mathrm{SO}_{4}^{2-}$. To confirm the $F_{\mathrm{S}}$ analysis, the concentration of the highly reactive hydroperoxy radical $\left(\mathrm{HO}_{2}\right)$ was also analyzed. The self-reaction of $\mathrm{HO}_{2}$ produces hydrogen peroxide $\left(\mathrm{H}_{2} \mathrm{O}_{2}\right)$, and this is the most effective oxidant of aqueousphase $\mathrm{SO}_{2}$ (Pandis and Seinfeld, 1989). Because the analyzed period was in winter, aqueous-phase reactions would be the main pathway for producing $\mathrm{SO}_{4}^{2-}$.

For $\mathrm{NO}_{3}^{-}$, the conversion ratios of $F_{\mathrm{n}}$ are defined by considering the concentration of $\mathrm{NO}_{2}$ as a precursor and calculated based on molar concentrations (Khoder, 2002):

$F_{n}=\frac{\left[\mathrm{HNO}_{3}\right]+\left[\mathrm{NO}_{3}^{-}\right]}{\left[\mathrm{NO}_{2}\right]+\left[\mathrm{HNO}_{3}\right]+\left[\mathrm{NO}_{3}^{-}\right]}\left[\mathrm{mol} \mathrm{mol}^{-1}\right]$.

To investigate the ratio of $\mathrm{NO}_{3}^{-}$to gas- and aerosol-phase components analogous to the calculation for $\mathrm{SO}_{4}^{2-}$, the conversion ratio of $F_{n}^{\prime}$ is introduced:

$F_{n}^{\prime}=\frac{\left[\mathrm{NO}_{3}^{-}\right]}{\left[\mathrm{HNO}_{3}\right]+\left[\mathrm{NO}_{3}^{-}\right]}\left[\mathrm{mol} \mathrm{mol}^{-1}\right]$.
The behavior of SNA is determined by introducing candidate indicators according to the work of Ansari and Pandis (1998) and Pinder et al. (2008). The gas ratio (GR) is an indicator of the sensitivity of $\mathrm{NO}_{3}^{-}$to changes in $\mathrm{SO}_{4}^{2-}$ and $\mathrm{NH}_{4}^{+}$concentrations. The GR is defined as the ratio of free ammonia to total nitrate as

$\mathrm{GR}=\frac{\left[\mathrm{NH}_{3}+\mathrm{NH}_{4}^{+}\right]-2\left[\mathrm{SO}_{4}^{2-}\right]}{\left[\mathrm{HNO}_{3}+\mathrm{NO}_{3}^{-}\right]}\left[\mathrm{mol} \mathrm{mol}^{-1}\right]$,

where it is assumed that $\mathrm{SO}_{4}^{2-}$ is fully neutralized, as indicated by the coefficient of 2 for $\left[\mathrm{SO}_{4}^{2-}\right]$. The GR value implies the following condition for $\mathrm{NO}_{3}^{-}$production:

$\left\{\begin{array}{l}\mathrm{GR}>1: \mathrm{NH}_{3} \text {-rich } \\ 0<\mathrm{GR}<1: \mathrm{NH}_{3} \text {-neutral } . \\ \mathrm{GR}<0: \mathrm{NH}_{3} \text {-poor }\end{array}\right.$

Here, $\mathrm{NH}_{3}$-rich means that there is sufficient $\mathrm{NH}_{3}$ to neutralize both $\mathrm{SO}_{4}^{2-}$ and $\mathrm{NO}_{3}^{-}, \mathrm{NH}_{3}$-neutral means that there is sufficient $\mathrm{NH}_{3}$ to neutralize $\mathrm{SO}_{4}^{2-}$, and $\mathrm{NH}_{3}$-poor means that there is insufficient $\mathrm{NH}_{3}$ to neutralize $\mathrm{SO}_{4}^{2-}$ or $\mathrm{NO}_{3}^{-}$. Free ammonia, which can form $\mathrm{NH}_{4} \mathrm{NO}_{3}$ in the equilibrium 
Path analysis along backward trajectory $\mathrm{TN}_{\mathrm{N}}$

(a)

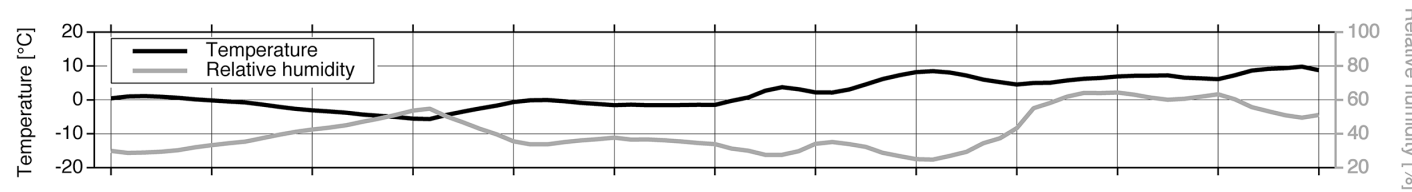

(b)

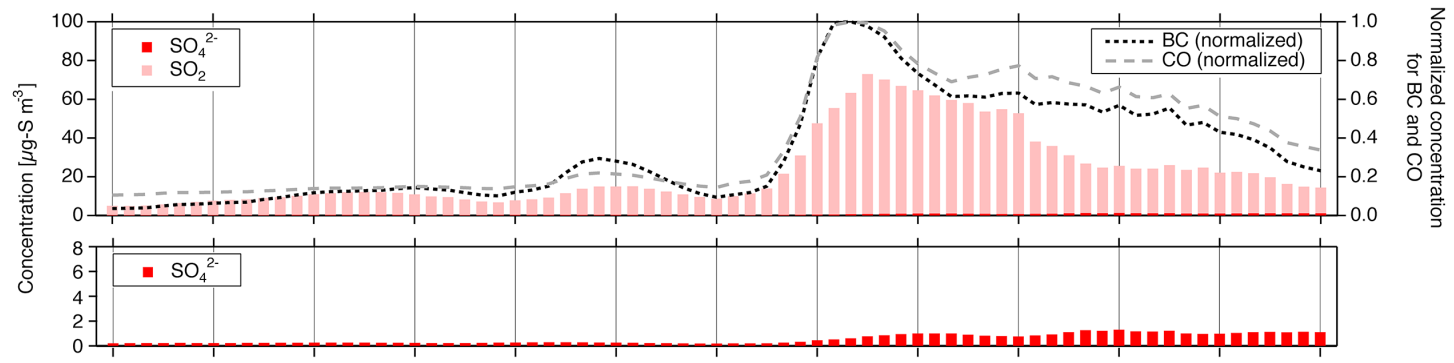

(c)

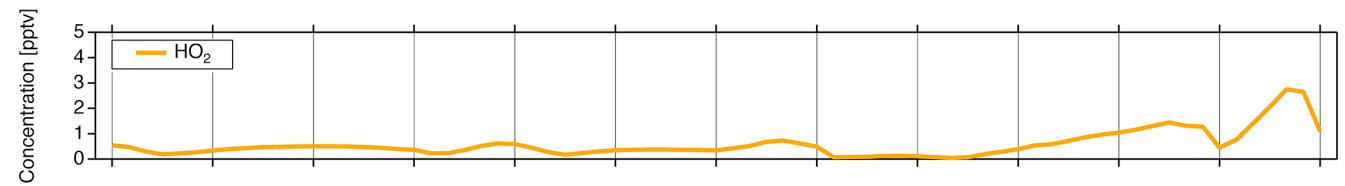

(d)

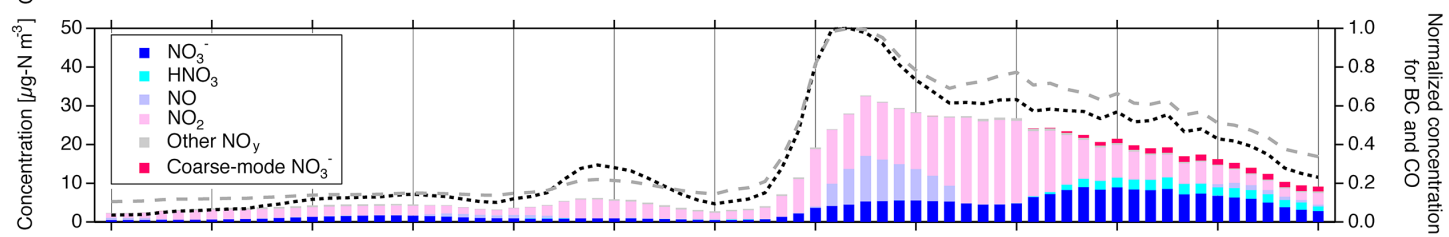

(e)

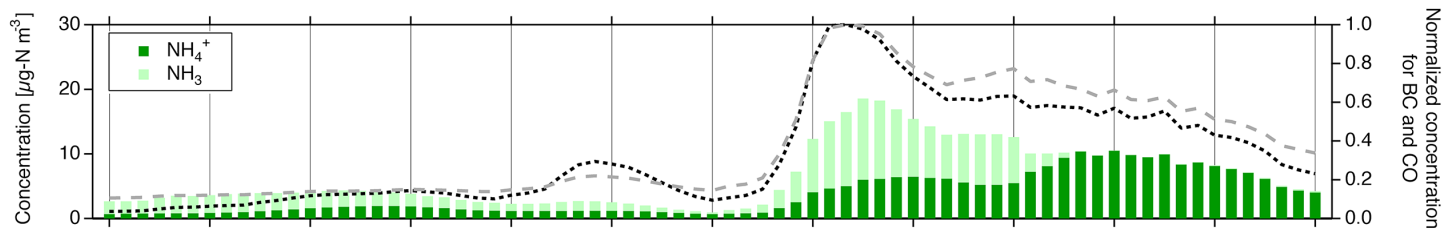

(f)

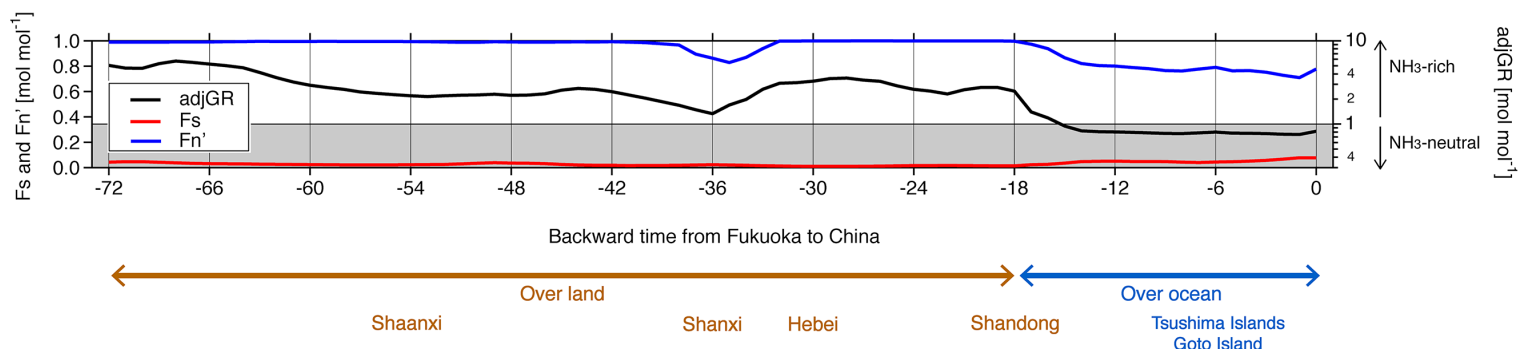

Figure 11. The path analysis of the model results along trajectory $T_{\mathrm{N}}$. (a) Temperature and relative humidity; (b) $\mathrm{SO}_{4}^{2-}$ (with expansion at the bottom) and $\mathrm{SO}_{2}$; (c) $\mathrm{HO}_{2}$ concentration, (d) $\mathrm{NO}_{3}^{-}, \mathrm{HNO}_{3}, \mathrm{NO}, \mathrm{NO}_{2}$, other $\mathrm{NOy}\left(\mathrm{NO}_{3}, \mathrm{HNO}_{2}, \mathrm{~N}_{2} \mathrm{O}_{5}\right.$, and PANs), and coarse-mode $\mathrm{NO}_{3}^{-} ;(\mathbf{e}) \mathrm{NH}_{4}^{+}$and $\mathrm{NH}_{3}$; (f) adjGR, $F_{\mathrm{s}}$, and $F_{n}^{\prime}$. In (b), (d), and (e), BC and $\mathrm{CO}$ concentrations normalized to the maximum value are also shown. The time axis indicates the backward time from Fukuoka. The brown and blue bars at the bottom are schematic images of the trajectory location over land and ocean.

process, is quantified more accurately by adjusting $\left[\mathrm{SO}_{4}^{2-}\right]$ with the degree of sulfate neutralization (DSN). The DSN is defined as

$\mathrm{DSN}=\frac{\left[\mathrm{NH}_{4}^{+}\right]-\left[\mathrm{NO}_{3}^{-}\right]}{\left[\mathrm{SO}_{4}^{2-}\right]}\left[\mathrm{mol} \mathrm{mol}^{-1}\right]$,

where DSN is equal to or greater than 2 if there is sufficient $\mathrm{NH}_{4}^{+}$. By substituting the coefficient 2 before $\left[\mathrm{SO}_{4}^{2-}\right.$ ] in Eq. (2) with Eq. (4), the adjusted GR (adjGR) can be defined as

$$
\begin{aligned}
\operatorname{adjGR} & =\frac{\left[\mathrm{NH}_{3}+\mathrm{NH}_{4}^{+}\right]-\mathrm{DSN} \times\left[\mathrm{SO}_{4}^{2-}\right]}{\left[\mathrm{HNO}_{3}+\mathrm{NO}_{3}^{-}\right]} \\
& =\frac{\left[\mathrm{NH}_{3}\right]+\left[\mathrm{NO}_{3}^{-}\right]}{\left[\mathrm{HNO}_{3}\right]+\left[\mathrm{NO}_{3}^{-}\right]}\left[\mathrm{mol} \mathrm{mol}^{-1}\right]
\end{aligned}
$$


Path analysis along backward trajectory Ts

(a)

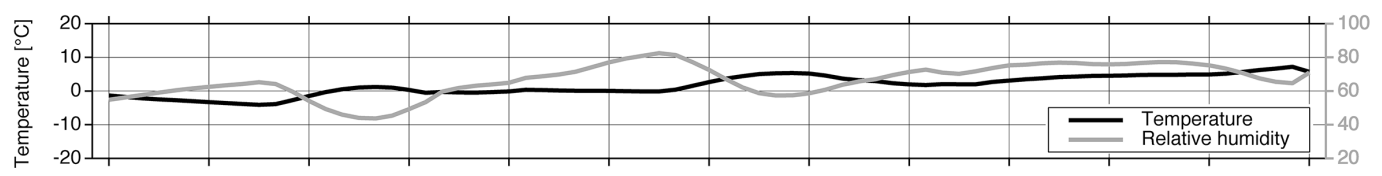

(b)

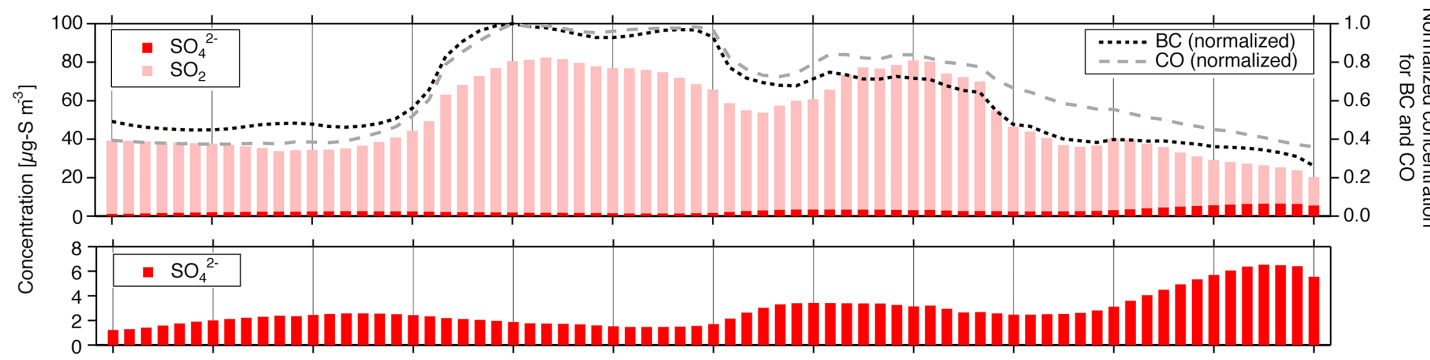

(c)

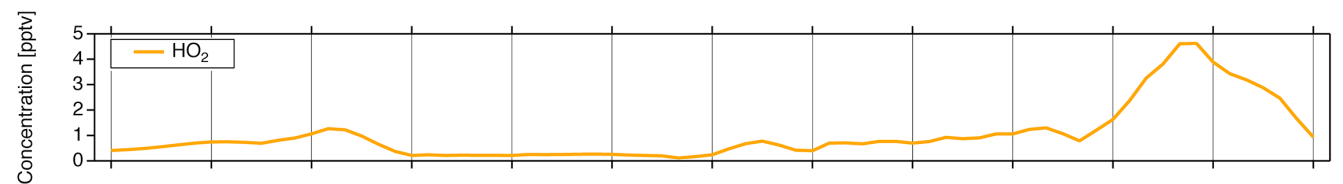

(d)

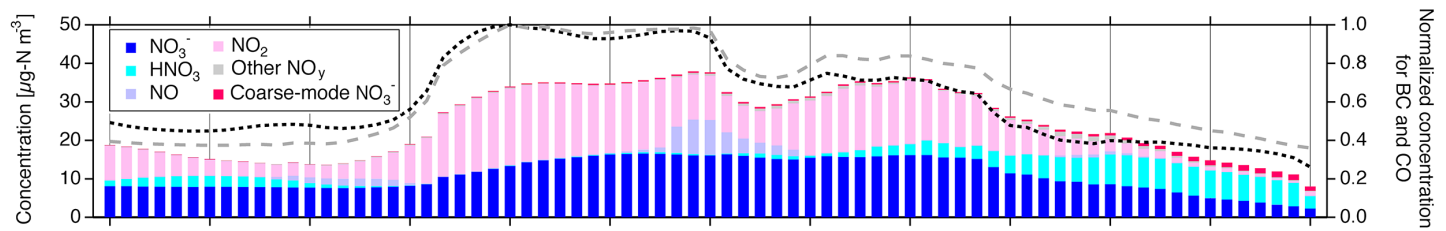

(e)

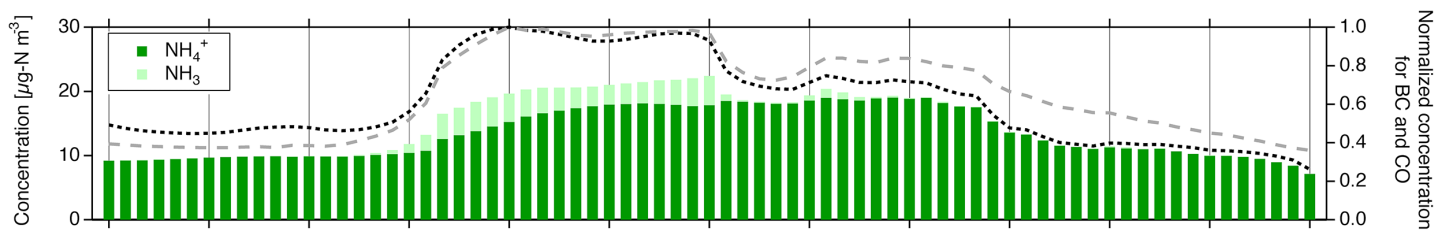

(f)

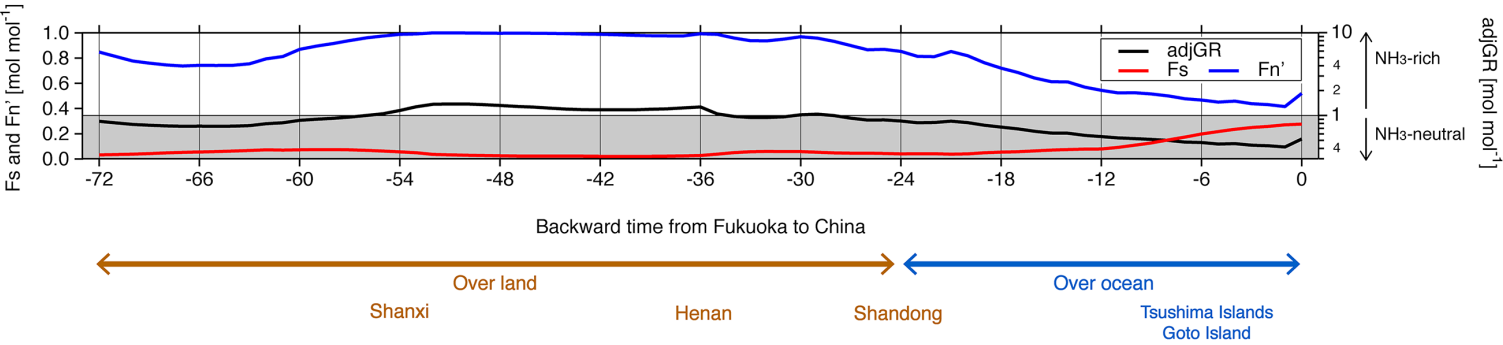

Figure 12. The path analysis of the model results along trajectory $T_{\mathrm{S}}$. (a) Temperature and relative humidity; (b) $\mathrm{SO}_{4}^{2-}$ (with expansion at the bottom) and $\mathrm{SO}_{2}$; (c) $\mathrm{HO}_{2}$ concentration; (d) $\mathrm{NO}_{3}^{-}, \mathrm{HNO}_{3}, \mathrm{NO}, \mathrm{NO}_{2}$, other $\mathrm{NO}_{y}\left(\mathrm{NO}_{3}, \mathrm{HNO}_{2}, \mathrm{~N}_{2} \mathrm{O}_{5}\right.$, and PANs), and coarse-mode $\mathrm{NO}_{3}^{-}$; (e) $\mathrm{NH}_{4}^{+}$and $\mathrm{NH}_{3}$; (f) adjGR, $F_{\mathrm{s}}$, and $F_{n}^{\prime}$. In (b), (d), and (e), BC and CO concentrations normalized to the maximum value are also shown. The time axis indicates the backward time from Fukuoka. The brown and blue bars at the bottom are schematics of the trajectory location over land and ocean.

by using the indexes, and the path analysis of the backward trajectories for the model results are shown in Figs. 11 and 12 and summarized in Table 2. The analyses are shown for the following: (a) the meteorological components of temperature and relative humidity; (b) $\mathrm{SO}_{4}^{2-}$ and $\mathrm{SO}_{2}$ with an enlarged view for $\mathrm{SO}_{4}^{2-}$; (c) $\mathrm{HO}_{2}$ concentration; (d) $\mathrm{NO}_{3}^{-}, \mathrm{HNO}_{3}, \mathrm{NO}$, $\mathrm{NO}_{2}$, other $\mathrm{NOy}$ consisting of $\mathrm{NO}_{3}, \mathrm{HNO}_{2}, \mathrm{~N}_{2} \mathrm{O}_{5}$, and peroxyacyl nitrates (PANs), and coarse-mode $\mathrm{NO}_{3}^{-}$; (e) $\mathrm{NH}_{4}^{+}$ and $\mathrm{NH}_{3}$; and (f) adjGR, $F_{\mathrm{s}}$, and $F_{n}^{\prime}$. The concentrations of the air pollutants were reduced by chemical reactions, dispersion, and deposition during the transport; therefore, as an index of the dispersion and deposition processes, $\mathrm{BC}$ and $\mathrm{CO}$ concentrations normalized to their maximum concentrations during the transport were used in the variation of the total concentration in (b), (d), and (e). Table 2 shows the meteorological components and the air pollutant concentrations 
of each component and total sulfate, total nitrate, and total ammonia. The indexes were averaged over China, the transport time above the ocean, and Fukuoka. The SNA concentration was balanced between $\mathrm{NH}_{4}^{+}$and $\mathrm{SO}_{4}^{2-}$ with $\mathrm{NO}_{3}^{-}$during both types $\mathrm{N}$ and $\mathrm{S}$.

During the type N pattern (Fig. 11), the concentration of air pollutants increased after the air mass moved into Hebei Province $(-30 \mathrm{~h})$. The relative humidity was lower than $40 \%$ when the air mass traveled over Shanxi Province and Hebei Province (Fig. 11a). The $\mathrm{SO}_{4}^{2-}$ concentration was around $1 \mu \mathrm{g}-\mathrm{S} \mathrm{m}^{-3}$ during transport (Fig. $11 \mathrm{~b}$ and Table 2), and $\mathrm{SO}_{2}$ was dominant in the total sulfate concentration. In this type $\mathrm{N}$ pattern, the concentration of the most effective oxidant of $\mathrm{HO}_{2}$ for the $\mathrm{SO}_{2}$ aqueous-phase reaction was smaller due to the lower relative humidity (Fig. 11c), and the conversion ratio was less than 0.1 (Fig. 11f and Table 2). Compared with the $\mathrm{SO}_{4}^{2-}$ variation, as the trajectory passed from Shanxi Province $(-36 \mathrm{~h})$ to Shandong Province $(-18 \mathrm{~h})$ and over the ocean $(-12 \mathrm{~h})$, the $\mathrm{NO}_{3}^{-}$and $\mathrm{NH}_{4}^{+}$concentrations increased. The concentrations of $\mathrm{NO}_{3}^{-}$and $\mathrm{NH}_{4}^{+}$decreased as the air mass traveled to Japan (Figs. 11d and 11e). Over China ( -30 to $-18 \mathrm{~h}$ ), gas-phase $\mathrm{NH}_{3}$ was abundant and $\mathrm{HNO}_{3}$ was fully consumed to produce $\mathrm{NH}_{4} \mathrm{NO}_{3}$ (Figs. 11d and e). The excess $\mathrm{HNO}_{3}$ over the ocean contributed to producing coarse-mode $\mathrm{NO}_{3}^{-}$by reacting with sea salt particles as the air mass traveled over the ocean (Fig. 11d). The adjGR was super $\mathrm{NH}_{3}-$ rich over China (Fig. 11f). After the air mass left Shandong, $\mathrm{HNO}_{3}$ increased and $\mathrm{NH}_{3}$ was close to zero (Fig. 11d and e), so the adjGR shifted to an $\mathrm{NH}_{3}$-neutral status (Fig. 11f). Consequently, the proportion of $\mathrm{NO}_{3}^{-}$, indicated by $F_{n}^{\prime}$, remained around $80 \%$ during transport from China to Japan (Fig. 11f). The rates of the decrease in total sulfate, total nitrate, and total ammonia were generally consistent with the rates of decrease in normalized $\mathrm{BC}$ and $\mathrm{CO}$, suggesting that the budget was almost satisfied during transport (Table 2). The decrease in $\mathrm{BC}$ was larger than that in $\mathrm{CO}$ because of wet deposition (e.g., Pan et al., 2011; Kanaya et al., 2016).

During the type S pattern (Fig. 12), SNA concentrations were higher compared with the type N pattern (Fig. 11), partly due to the slower motion of the air mass compared with type N. $\mathrm{SO}_{4}^{2-}$ concentration was around $2 \mu \mathrm{g}-\mathrm{S} \mathrm{m}^{-3}$ over Shanxi Province to Henan Province ( -72 to $-36 \mathrm{~h}$ ). It increased slightly to $3 \mu \mathrm{g}-\mathrm{S} \mathrm{m}^{-3}$ over Henan Province to Shandong Province $(-36$ to $-24 \mathrm{~h})$ and subsequently increased to $3 \mu \mathrm{g}-\mathrm{S} \mathrm{m}^{-3}$ over the ocean (Fig. 12b and Table 2). The aqueous-phase reaction contributed to the production, as suggested by the variation in $\mathrm{HO}_{2}$ concentration. Over the oceans, the relative humidity was around $80 \%$, which is $20 \%$ larger than in the case of the type N pattern (Fig. 12a and Table 2). The $F_{\mathrm{s}}$ conversion ratio was 0.3 when the air mass reached Fukuoka (Fig. 12f). The increase in $\mathrm{SO}_{4}^{2-}$ over Fukuoka compared with over China was $+67.2 \%$ (Table 2). The behavior of gas-phase $\mathrm{HNO}_{3}$ and $\mathrm{NH}_{3}$ was similar in type $\mathrm{N}$ patterns (Figs. 12d and e); the $\mathrm{NH}_{3}$ concentration was high over China, and $\mathrm{HNO}_{3}$ gradually increased after the air mass approached the ocean, partly because coarsemode $\mathrm{NO}_{3}^{-}$was produced. However, the $\mathrm{NH}_{3}$ concentration was smaller compared with type $\mathrm{N}$ patterns and remained near zero when the air mass passed over Henan Province (Fig. 12e). The adjGR showed a slight $\mathrm{NH}_{3}$-rich status over China ( -54 to $-36 \mathrm{~h}$ ) and shifted to an $\mathrm{NH}_{3}$-neutral status before the air mass left China $(-36 \mathrm{~h})$. At the same time, the ratio of $\mathrm{NO}_{3}^{-}$, indicated by $F_{n}^{\prime}$, decreased to 0.45 (Fig. $12 \mathrm{f}$ and Table 2). Similar to type $\mathrm{N}$, the rates of decrease in total sulfate, total nitrate, and total ammonia were generally consistent with the rates of decrease in normalized $\mathrm{BC}$ and $\mathrm{CO}$.

To summarize the key points for type $\mathrm{N}$ and $\mathrm{S}$ patterns, the behavior of $\mathrm{SO}_{4}^{2-}, \mathrm{NO}_{3}^{-}$, and $\mathrm{HNO}_{3}$ concentrations during transport from China to Japan is shown in Fig. 13. The relative percentages of the concentration of each species to the total concentration of $\mathrm{SO}_{4}^{2-}, \mathrm{NO}_{3}^{-}$, and $\mathrm{HNO}_{3}$ are shown. It is clear that $\mathrm{NO}_{3}^{-}$was not produced, whereas $\mathrm{SO}_{4}^{2-}$ was produced during transport from China to Fukuoka. Types $\mathrm{N}$ and $\mathrm{S}$ both showed the dominance of $\mathrm{NH}_{4} \mathrm{NO}_{3}$ (over $70 \%$ ) when the air mass was over China $(-48 \mathrm{~h})$. For the air mass close to Fukuoka, because there was no $\mathrm{NH}_{3}, \mathrm{NH}_{4} \mathrm{NO}_{3}$ decomposed into gas-phase $\mathrm{NH}_{3}$ and $\mathrm{HNO}_{3}$. Therefore, $\mathrm{HNO}_{3}$ concentration increased as the air mass reached Fukuoka for types $\mathrm{N}$ and $\mathrm{S}$. At this time, the $\mathrm{SO}_{4}^{2-}$ concentration was important in determining the $\mathrm{NO}_{3}^{-}$concentration. $\mathrm{SO}_{4}^{2-}$ production (Figs. $11 \mathrm{~b}$ and $12 \mathrm{~b}$ ) through an aqueous-phase reaction was indicated by the $\mathrm{HO}_{2}$ concentration (Figs. 11c and $12 \mathrm{c}$ ), and $F_{\mathrm{s}}$ showed a large difference between types $\mathrm{N}$ (lower than 0.1 during transport; Fig. 11f) and $\mathrm{S}$ (around 0.3 at Fukuoka; Fig. 12f). Once $\mathrm{H}_{2} \mathrm{SO}_{4}$ was produced via an aqueous-phase reaction, it reacted with gas-phase $\mathrm{NH}_{3}$ to produce $\left(\mathrm{NH}_{4}\right)_{2} \mathrm{SO}_{4}$, leading to the further decomposition of $\mathrm{NH}_{4} \mathrm{NO}_{3}$. The ratio of $\mathrm{NO}_{3}^{-}\left(F_{n}^{\prime}\right)$ showed different behavior for types $\mathrm{N}$ (around 0.8 during transport; Figs. 11f) and $\mathrm{S}$ (lower than 0.5 at Fukuoka; Fig. 12f). The transport pattern under similar conditions over China was determined by the low $\mathrm{SO}_{4}^{2-}$ concentration maintaining a higher $\mathrm{NO}_{3}^{-}$concentration at Fukuoka (type N), or by $\mathrm{SO}_{4}^{2-}$ production under a higher relative humidity resulting in the dominance of $\mathrm{SO}_{4}^{2-}$ with further $\mathrm{NH}_{4} \mathrm{NO}_{3}$ decomposition (type $\mathrm{S}$ ).

\subsection{Outflow analysis}

Finally, the outflow of $\mathrm{SO}_{4}^{2-}$ and $\mathrm{NO}_{3}^{-}$from China to western Japan during the intensive observation campaign is summarized in Fig. 14. In this figure, the modeled $\mathrm{SO}_{4}^{2-}$ and $\mathrm{NO}_{3}^{-}$ concentrations were averaged at $32-36^{\circ} \mathrm{N}$ to cover the four sites in Japan (Fig. 1) and are shown as a time-longitude cross section. The longitudes of Shanghai, the Goto Islands, Tsushima Island, Fukuoka, and Tottori are indicated at the bottom of the figure. This outflow analysis can help to identify the areas affected by transboundary heavy pollution. A main outflow from China to western Japan occurred twice 
Table 2. Summary of the path analysis for types $\mathrm{N}$ and $\mathrm{S}$.

\begin{tabular}{|c|c|c|c|c|c|c|}
\hline \multirow[t]{2}{*}{$\begin{array}{l}\text { Type } \\
\text { Arrival time at Fukuoka } \\
\text { Transport time from China }\end{array}$} & \multicolumn{3}{|c|}{$\begin{array}{c}\text { Type N } \\
\text { 15:00 LT, } 11 \text { Jan } \\
18 \mathrm{~h}\end{array}$} & \multicolumn{3}{|c|}{$\begin{array}{c}\text { Type S } \\
\text { 00:00 LT, } 17 \text { Jan } \\
24 \mathrm{~h}\end{array}$} \\
\hline & Over China & During transport & Over Fukuoka & Over China & During transport & Over Fukuoka \\
\hline Temperature $\left[{ }^{\circ} \mathrm{C}\right]$ & 6.6 & 6.7 & 9.3 & 3.1 & 4.0 & 6.5 \\
\hline Relative humidity [\%] & 32.7 & 60.5 & 50.5 & 66.3 & 74.4 & 67.0 \\
\hline $\mathrm{SO}_{4}^{2-}\left[\mu \mathrm{g}-\mathrm{S} \mathrm{m}^{-3}\right]$ & 0.9 & $\begin{array}{r}1.1 \\
(+24.5 \%)\end{array}$ & $\begin{array}{r}1.1 \\
(+25.5 \%)\end{array}$ & 3.3 & $\begin{array}{r}3.7 \\
(+14.1 \%)\end{array}$ & $\begin{array}{r}6.2 \\
(+67.2 \%)\end{array}$ \\
\hline $\mathrm{SO}_{2}\left[\mu \mathrm{g}-\mathrm{S} \mathrm{m}^{-3}\right]$ & 55.9 & 25.0 & 14.1 & 72.1 & 40.0 & 17.0 \\
\hline Total sulfate $\left[\mu \mathrm{g}-\mathrm{S} \mathrm{m}^{-3}\right]$ & 56.8 & $\begin{array}{r}26.1 \\
(-54.1 \%)\end{array}$ & $\begin{array}{r}15.2 \\
(-74.7 \%)\end{array}$ & 75.4 & $\begin{array}{r}43.8 \\
(-41.9 \%)\end{array}$ & $\begin{array}{r}23.1 \\
(-73.2 \%)\end{array}$ \\
\hline$F_{\mathrm{S}}\left[\mathrm{mol} \mathrm{mol}^{-1}\right]$ & 0.02 & 0.04 & 0.07 & 0.04 & 0.10 & 0.27 \\
\hline $\mathrm{NO}_{3}^{-}\left[\mu \mathrm{g}-\mathrm{N} \mathrm{m}^{-3}\right]$ & 4.9 & $\begin{array}{r}7.5 \\
(+53.6 \%)\end{array}$ & $\begin{array}{r}3.3 \\
(-42.0 \%)\end{array}$ & 15.9 & $\begin{array}{r}9.4 \\
(-41.1 \%)\end{array}$ & $\begin{array}{r}2.8 \\
(-85.6 \%)\end{array}$ \\
\hline $\mathrm{HNO}_{3}\left[\mu \mathrm{g}-\mathrm{N} \mathrm{m}^{-3}\right]$ & 0.0 & 2.1 & 1.7 & 1.9 & 6.1 & 5.2 \\
\hline Other $\mathrm{NO}_{y}\left[\mu \mathrm{g}-\mathrm{N} \mathrm{m}^{-3}\right]$ & 22.2 & 8.5 & 3.3 & 16.7 & 6.4 & 0.9 \\
\hline Coarse-mode $\mathrm{NO}_{3}^{-}\left[\mu \mathrm{g}-\mathrm{N} \mathrm{m}^{-3}\right]$ & 0.0 & 1.1 & 1.4 & 0.4 & 0.7 & 1.4 \\
\hline Total $\mathrm{NO}_{y}\left[\mu \mathrm{g}-\mathrm{Nm}^{-3}\right]$ & 27.1 & $\begin{array}{r}19.1 \\
(-29.3 \%)\end{array}$ & $\begin{array}{r}9.7 \\
(-66.2 \%)\end{array}$ & 34.8 & $\begin{array}{r}22.5 \\
(-35.3 \%)\end{array}$ & $\begin{array}{r}10.4 \\
(-77.0 \%)\end{array}$ \\
\hline$F_{n}^{\prime}\left[\mathrm{mol} \mathrm{mol}^{-1}\right]$ & 1.00 & 0.81 & 0.73 & 0.90 & 0.61 & 0.45 \\
\hline $\mathrm{NH}_{4}^{+}\left[\mu \mathrm{g}-\mathrm{N} \mathrm{m}^{-3}\right]$ & 5.6 & $\begin{array}{r}8.7 \\
(+54.3 \%)\end{array}$ & $\begin{array}{r}4.4 \\
(-28.9 \%)\end{array}$ & 18.8 & $\begin{array}{r}12.6 \\
(-33.0 \%)\end{array}$ & $\begin{array}{r}8.2 \\
(-62.1 \%)\end{array}$ \\
\hline $\mathrm{NH}_{3}\left[\mu \mathrm{g}-\mathrm{N} \mathrm{m}^{-3}\right]$ & 7.5 & 0.4 & 0.2 & 0.6 & 0.1 & 0.0 \\
\hline Total ammonia $\left[\mu \mathrm{g}-\mathrm{N} \mathrm{m}^{-3}\right]$ & 13.2 & $\begin{array}{r}9.1 \\
(-30.7 \%)\end{array}$ & $\begin{array}{r}4.6 \\
(-67.9 \%)\end{array}$ & 19.5 & $\begin{array}{r}12.7 \\
(-34.8 \%)\end{array}$ & $\begin{array}{r}8.2 \\
(-63.3 \%)\end{array}$ \\
\hline $\operatorname{adjGR}\left[\mathrm{mol} \mathrm{mol}^{-1}\right]$ & 2.56 & 0.87 & 0.77 & 0.93 & 0.61 & 0.46 \\
\hline $\mathrm{BC}\left[\mu \mathrm{g} \mathrm{m}^{-3}\right]$ & 6.5 & $\begin{array}{r}5.2 \\
(-20.2 \%) \\
\end{array}$ & $\begin{array}{r}2.6 \\
(-63.3 \%) \\
\end{array}$ & 9.7 & $\begin{array}{r}6.1 \\
(-37.4 \%) \\
\end{array}$ & $\begin{array}{r}4.0 \\
(-63.9 \%) \\
\end{array}$ \\
\hline $\mathrm{CO}[\mathrm{ppbv}]$ & 904.4 & $\begin{array}{r}737.6 \\
(-18.4 \%) \\
\end{array}$ & $\begin{array}{r}440.2 \\
(-53.8 \%) \\
\end{array}$ & 1260.0 & $\begin{array}{r}887.0 \\
(-29.8 \%) \\
\end{array}$ & $\begin{array}{r}564.9 \\
(-56.8 \%) \\
\end{array}$ \\
\hline Key points & $\begin{array}{l}\text { - Dominance } \\
\text { - Under } 10 \% \\
\text { - Lower relat } \\
\text { - Abundant } \mathrm{I} \\
\text { - } \mathrm{NH}_{3} \text {-rich a }\end{array}$ & $\begin{array}{l}\text { of } \mathrm{NO}_{3}^{-} \text {compared } \\
\text { conversion ratio } \mathrm{f} \\
\text { ive humidity } \\
\mathrm{JH}_{3} \text { supply above } \\
\text { ir mass maintaining }\end{array}$ & ization of $\mathrm{NO}_{3}^{-}$ & $\begin{array}{l}\text { - Dominanc } \\
\text { - Approxim } \\
\text { - Higher rel } \\
\text { - } \mathrm{No} \mathrm{NH}_{3} \mathrm{i} \\
\text { - } \mathrm{NH}_{3} \text {-neut }\end{array}$ & $\begin{array}{l}\text { of } \mathrm{SO}_{4}^{2-} \text { compared } \\
\text { ely } 30 \% \text { conversio } \\
\text { ive humidity of aro } \\
\text { the gas phase } \\
1 \text { conditions during }\end{array}$ & $\begin{array}{l}\mathrm{O}_{4}^{2-} \\
\mathrm{O}_{4}^{2-} \text { neutralized }\end{array}$ \\
\hline
\end{tabular}

Note: the parentheses indicate the multiplying factors compared with the status over China. The status is averaged over $6 \mathrm{~h}$ before the air mass leaves China, during the transport time from China to Fukuoka above the ocean, and over $3 \mathrm{~h}$ before the air mass reaches Fukuoka. Other $\mathrm{NO}_{y}$ consists of $\mathrm{NO}, \mathrm{NO}_{2}, \mathrm{NO}_{3}, \mathrm{HNO}_{2}, \mathrm{~N}_{2} \mathrm{O}_{5}$, and PANs.

(types $\mathrm{N}$ and $\mathrm{S}$ ). The outflow concentration of $\mathrm{SO}_{4}^{2-}$ was lower on 11 January for type $\mathrm{N}$ and larger on 17 January for type $\mathrm{S}$; a high concentration of more than $15 \mu \mathrm{g} \mathrm{m}^{-3}$ reached $130^{\circ} \mathrm{N}$ (Fukuoka) and a concentration of around $10 \mu \mathrm{g} \mathrm{m}^{-3}$ reached $134^{\circ} \mathrm{N}$ (Tottori) for type $\mathrm{S}$ (Fig. 14a). The outflow of $\mathrm{NO}_{3}^{-}$was observed over the Goto Islands, Tsushima Island, and Fukuoka on 11 January for type N, whereas the high concentration of over $10 \mu \mathrm{g} \mathrm{m}^{-3}$ was limited to the East China Sea region on 17 January for type S. A concentration of $\mathrm{NO}_{3}^{-}$of more than $5 \mu \mathrm{g} \mathrm{m}^{-3}$ did not reach $134^{\circ} \mathrm{N}$ (Tottori) for type $\mathrm{N}$ (Fig. 14b). The outflow analysis suggested that $\mathrm{SO}_{4}^{2-}$ can be transported over longer distances, whereas transboundary $\mathrm{NO}_{3}^{-}$air pollution is limited to western Japan, especially over Kyushu.

\section{Conclusion}

Using state-of-the-art observation systems to capture SNA behavior and a chemical transport model, two episodes of high $\mathrm{PM}_{2.5}$ concentrations of around $100 \mu \mathrm{g} \mathrm{m}^{-3}$ were analyzed that occurred in winter over western Japan. The first episode (11 January) was dominated by $\mathrm{NO}_{3}^{-}$(type $\mathrm{N}$ ) and the second episode (17 January) by $\mathrm{SO}_{4}^{2-}$ (type $\mathrm{S}$ ). The chemical transport model captured the behavior of SNA and the related gas-phase species of $\mathrm{HNO}_{3}$ and $\mathrm{NH}_{3}$ as well as coarse-mode $\mathrm{NO}_{3}^{-}$observed over Japan. The model also reproduced $\mathrm{PM}_{2.5}$ variation over China. To evaluate the domestic contributions, a sensitivity analysis was performed. In this analysis, the anthropogenic emissions from Japan were switched off in the chemical transport model. The results showed some domestic contributions for $\mathrm{NO}_{3}^{-}$, although the 
(a) Path analysis along backward trajectory $\mathrm{TN}_{\mathrm{N}}$

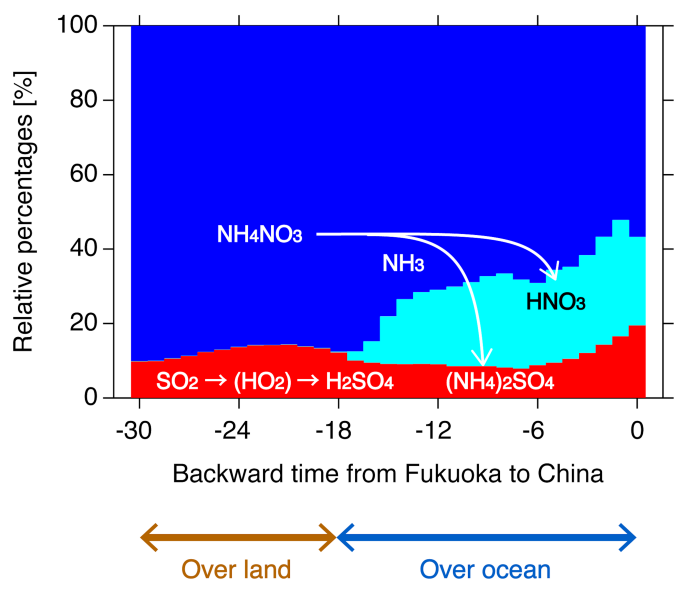

(b) Path analysis along backward trajectory Ts

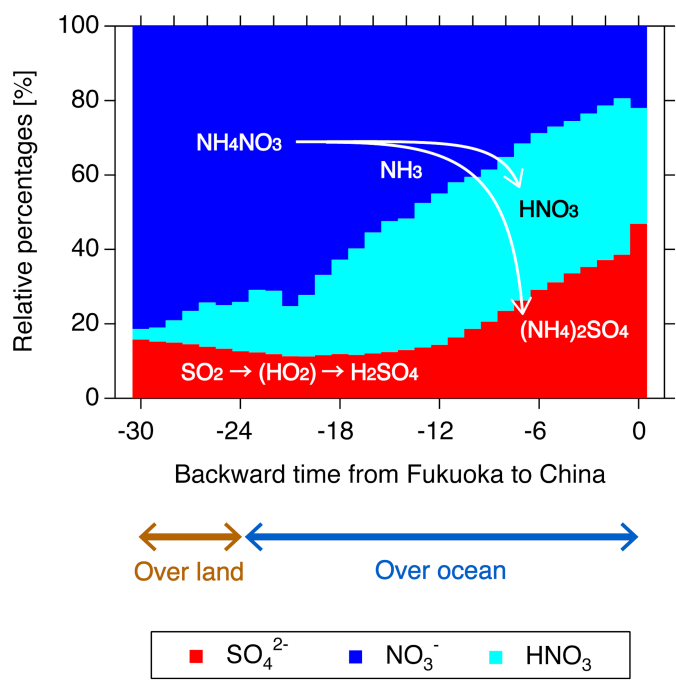

Figure 13. The path analysis of the model results along trajectories $T_{\mathrm{N}}$ and $T_{\mathrm{S}}$. The percentages of each concentration relative to the sum of the $\mathrm{SO}_{4}^{2-}, \mathrm{NO}_{3}^{-}$, and $\mathrm{HNO}_{3}$ concentrations in equivalent units are shown. The time axis indicates the backward time from Fukuoka. The brown and blue bars at the bottom are schematics of the trajectory location over land and ocean.

type $\mathrm{N}$ and $\mathrm{S}$ patterns were dominated by transboundary air pollution, even at Fukuoka. The effects of transboundary air pollution on type $\mathrm{N}$ and $\mathrm{S}$ patterns were also confirmed by analyzing the behavior of $\mathrm{BC}$ at Fukuoka and the remote Goto Islands. The importance of transboundary air pollution for coarse-mode $\mathrm{NO}_{3}^{-}$, produced by abundant $\mathrm{HNO}_{3}$ and sea salt particles, was also revealed. To investigate the characteristic differences between type $\mathrm{N}$ and $\mathrm{S}$ patterns, the chemical transport model results were analyzed by backward trajectory analysis from Fukuoka to continental Asia. We also evaluated the adjusted gas ratio (adjGR), which indicates the sensitivity of $\mathrm{NO}_{3}^{-}$to changes in $\mathrm{SO}_{4}^{2-}$ and $\mathrm{NH}_{4}^{+}$, and examined $F_{\mathrm{s}}$, which is the conversion ratio of $\mathrm{SO}_{2}$ to $\mathrm{SO}_{4}^{2-}$. (a) $\mathrm{SO}_{4}{ }^{2-}$

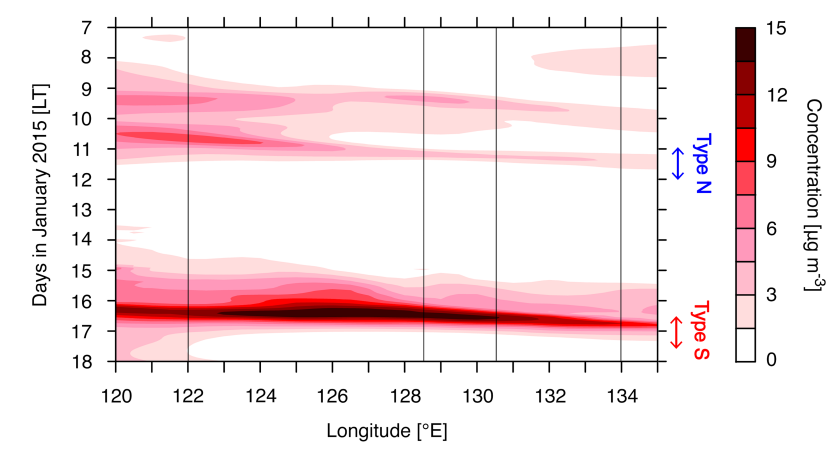

(b) $\mathrm{NO}_{3}^{-}$

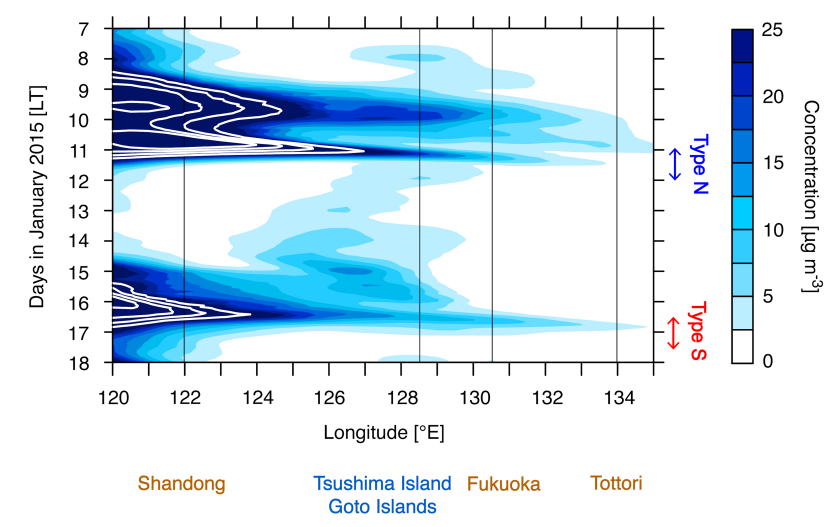

Figure 14. The outflow frequency of (a) $\mathrm{SO}_{4}^{2-}$ and (b) $\mathrm{NO}_{3}^{-}$. The contours shown by the white lines for $\mathrm{NO}_{3}^{-}$represent $30,40,50$, and $60 \mu \mathrm{g} \mathrm{m}^{-3}$. The model results are averaged over $32-36^{\circ} \mathrm{N}$ and are shown as a time-longitude cross section. The longitudes of the representative locations are indicated by the thin black lines, and the location names are written in brown and blue at the bottom of the figure.

For the $\mathrm{SO}_{2}$ aqueous-phase reaction, $\mathrm{H}_{2} \mathrm{O}_{2}$ is the most effective oxidant. Thus, $\mathrm{HO}_{2}$, which produces $\mathrm{H}_{2} \mathrm{O}_{2}$ through self-reaction, was also analyzed. The features of type $\mathrm{N}$ and $S$ patterns are summarized as follows.

- In the type $\mathrm{N}$ transport pattern, $\mathrm{NO}_{3}^{-}$was mainly the $\mathrm{NH}_{4}^{+}$counterion during transport from China to Japan. A high $\mathrm{NO}_{3}^{-}$concentration of more than $10 \mu \mathrm{g} \mathrm{m}^{-3}$ was observed at Fukuoka. $\mathrm{NH}_{3}$ was abundant and $\mathrm{HNO}_{3}$ was completely consumed to produce $\mathrm{NO}_{3}^{-}$over China; hence, the adjGR indicated an $\mathrm{NH}_{3}$-rich status, which meant full neutralization of both $\mathrm{SO}_{4}^{2-}$ and $\mathrm{NO}_{3}^{-}$over China. After the air mass left China, $\mathrm{HNO}_{3}$ increased and $\mathrm{NH}_{3}$ was close to zero, so the adjGR shifted to an $\mathrm{NH}_{3}$-neutral status. The $\mathrm{SO}_{4}^{2-}$ concentration was always lower than the $\mathrm{NO}_{3}^{-}$concentration. This was because the $\mathrm{HO}_{2}$ concentration was less than 3 pptv during transport from China to Fukuoka, and $F_{\mathrm{S}}$ suggested a slow conversion ratio for $\mathrm{SO}_{4}^{2-}$ of less 0.1 . $\mathrm{SO}_{4}^{2-}$ production via an aqueous-phase reaction was also inhib- 
ited. This also explained why the air mass maintained a higher $\mathrm{NO}_{3}^{-}$concentration during transport.

- In the type $\mathrm{S}$ transport pattern, the ion balance between $\mathrm{NH}_{4}^{+}$and $\mathrm{NO}_{3}^{-}$with $\mathrm{SO}_{4}^{2-}$ showed that the counterion of $\mathrm{NH}_{4}^{+}$was mainly $\mathrm{NO}_{3}^{-}$over China and then became $\mathrm{SO}_{4}^{2-}$ as the air mass left China and approached Fukuoka. A high concentration of $\mathrm{SO}_{4}^{2-}$ of more than $20 \mu \mathrm{g} \mathrm{m}^{-3}$ was observed at Fukuoka. The change in $F_{\mathrm{s}}$ from 0.1 to 0.3 when the air mass reached Fukuoka was consistent with this observation. Higher $F_{\mathrm{S}}$ values were related to higher relative humidity and $\mathrm{HO}_{2}$ concentrations, indicating the high production of $\mathrm{SO}_{4}^{2-}$ via an aqueous-phase reaction $\left(\mathrm{H}_{2} \mathrm{SO}_{4}\right)$. The production of $\mathrm{H}_{2} \mathrm{SO}_{4}$ promoted the reaction with $\mathrm{NH}_{3}$ to produce $\left(\mathrm{NH}_{4}\right)_{2} \mathrm{SO}_{4}$ and the further decomposition of $\mathrm{NH}_{4} \mathrm{NO}_{3}$ during the transport process from China to Fukuoka. The temporal behavior of gas-phase $\mathrm{HNO}_{3}$ and $\mathrm{NH}_{3}$ was similar for type $\mathrm{N}$; however, the $\mathrm{NH}_{3}$ concentration was lower. The adjGR showed almost $\mathrm{NH}_{3}$-neutral conditions during type $\mathrm{S}$. The production of $\mathrm{SO}_{4}^{2-}$ and the insufficient supply of $\mathrm{NH}_{3}$ contributed to the rapid decomposition of $\mathrm{NH}_{4} \mathrm{NO}_{3}$ in this case.

In this study, we clarified two types of transport patterns for SNA. The spatial distribution pattern of the outflow over East Asia in January 2015 showed that the outflow of $\mathrm{SO}_{4}^{2-}$ stretched over the whole of western Japan, whereas transboundary $\mathrm{NO}_{3}^{-}$air pollution played an important role over Kyushu in western Japan. Generally, transboundary air pollution dominated by $\mathrm{SO}_{4}^{2-}$ (type $\mathrm{S}$ ) has been recognized over East Asia, but we have elucidated the effect of transboundary heavy pollution dominated by $\mathrm{NO}_{3}^{-}$(type $\mathrm{N}$ ). Our findings demonstrate the importance of $\mathrm{NO}_{3}^{-}$long-range transport.

The study period was limited to January 2015 , so the analyzed period should be extended to investigate the type $S$ and $\mathrm{N}$ transport patterns further. The variation in the gas ratio for emissions (GRe), which considers the balance between $\mathrm{SO}_{2}$, $\mathrm{NO}_{x}$, and $\mathrm{NH}_{3}$ (analogous to Eq. 4), may be useful for future analysis. The emission reductions achieved by the 12th Chinese Five Year Plan for 2011-2015 (Asia Society, 2016) resulted in a GRe increase, which caused an $\mathrm{NH}_{3}$-rich status compared with the current status. Moreover, the target for the 13th Chinese Five Year Plan for 2016-2020 suggests that there will be further increases in GRe. The effects of different reduction rates for SNA precursor gases on transboundary $\mathrm{NO}_{3}^{-}$air pollution, especially over western Japan, should be modeled.

Data availability. To request observation data used in this study for scientific research purposes, please contact Itsushi Uno at Kyushu University via email (uno@riam.kyushu-u.ac.jp). Model simulations were based on CMAQ, open-source and publicly available software. The model and related software can be downloaded from https://www.cmascenter.org/download.cfm for registered users.
Author contributions. Itsushi Uno designed the synergetic observations at the Chikushi Campus of Kyushu University and other remote sites in western Japan. Shigekazu Yamamoto and Kazuo Osada respectively carried out the ground-based ACSA and $\mathrm{NH}_{x}$ monitor observations at Fukuoka. Yusuke Kamiguchi and Kazuo Osada conducted air sampling and chemical analysis for D-F pack samples during the intensive observation period at Fukuoka. Kazuo Osada and Yasunori Kurosaki measured $\mathrm{PM}_{2.5}$ and analyzed samples at Tottori. Kei Tamura analyzed the observations from the remote sites on Tsushima Island and the Goto Islands. Yugo Kanaya conducted the $\mathrm{BC}$ observations at Fukuoka and the Goto Islands. Zhe Wang and Syuichi Itahashi discussed the modeling configuration, and Zhe Wang conducted the model comparison to brush up the model results. Syuichi Itahashi developed the modeling system, performed the model simulations and analysis, and prepared the paper with the contributions from all coauthors.

Competing interests. The authors declare that they have no conflict of interest.

Acknowledgements. This work was supported by the Japan Society for the Promotion of Science (JSPS), KAKENHI grant numbers JP25220101, JP23310004, and JP15H02803 as well as by the Environment Research and Technology Development Fund of the Ministry of the Environment, Japan (nos. S-7, 2-1403, and $5-1505)$. This work was partly funded by a joint research program through the Arid Land Research Center at Tottori University (no. 28C2011) and by a collaborative research program through the Research Institute for Applied Mechanics at Kyushu University (no. 26AO-2, 27AO-6, 28AO-2, 28AO-10). We thank Sayako Ueda at Nagoya University for analyzing tape filters at Tottori University. We acknowledge the Ministry of the Environment, Japan, for providing the preliminary observation data at Tsushima before final production.

Edited by: F. Dentener

Reviewed by: three anonymous referees

\section{References}

Ansari, A. S. and Pandis, S. N.: response of inorganic PM to precursor conventrations, Environ. Sci. Technol., 32, 2706-2714, 1998.

Appel, B. R., Tokiwa, Y., and Haik, M.: Sampling of Nitrates in Ambient Air, Atmos. Environ., 15, 283-289, 1981.

Asia Society: https://www.chinafile.com/reporting-opinion/, last access: 1 September 2016.

Boylan, J. W. and Russell, A. G.: PM and light extinction model performance metrics, goals, and criteria for three-dimensional air quality models, Atmos. Environ., 40, 4946-4959, 2006.

Byun, D. W. and Schere, K. L.: Review of the governing equations, computational algorithms, and other components of the model3 community multiscale air quality (CMAQ) modeling system, Appl. Mech. Rev., 59, 51-77, 2006.

Carmichael, G. R., Calori, G., Hayami, H., Uno, I., Cho, S. Y., Engardt, M., Kim, S.-B., Ichikawa, Y., Ikeda, Y., Woo, J.-H., Ueda, H., and Amann, M.: The MICS-Asia study: model intercompar- 
ison of long-range transport and sulfur deposition in East Asia, Atmos. Environ., 36, 175-199, 2002.

Carmichael, G. R., Sakurai, T., Streets, D., Hozumi, Y., Ueda, H., Park, S. U., Fung, C., Han, Z., Kajino, M., Engardt, M., Bennet, C., Hayami, H., Sartelet, K., Holloway, T., Wang, Z., Kannari, A., Fu, J., Matsuda, K., Thongboonchoo, N., and Amann, M: MICS-Asia II: The model intercomparison study for Asia Phase II methodology and overview of findings, Atmos. Environ., 42, 3468-3490, 2008.

Chang, M. C., Sioutas, C., Kim, S., Gong Jr., H., and Linh, W. S.: Reduction of nitrate losses from filter and impactor samplers by means of concentration enrichment, Atmos. Environ., 34, 85-98, 2000.

Genfa, Z., Dasgupta, P. K., and Dong, S.: Measurement of Atmospheric Ammonia, Environ. Sci. Technol., 23, 1467-1474, 1989.

Guenther, A. B., Jiang, X., Heald, C. L., Sakulyanontvittaya, T., Duhl, T., Emmons, L. K., and Wang, X.: The Model of Emissions of Gases and Aerosols from Nature version 2.1 (MEGAN2.1): an extended and updated framework for modeling biogenic emissions, Geosci. Model Dev., 5, 1471-1492, doi:10.5194/gmd-51471-2012, 2012.

Huang, X., Song, Y., Li, M., Li, J., Huo, Q., Cai, X., Zhu, T., Hu, M., and Zhang, H.: A high-resolution ammonia emission inventory in China, Global Biogeochem. Cy., 26, GB1030, doi:10.1029/2011GB004161, 2012.

Ikeda, K., Yamaji, K., Kanaya, Y., Taketani, F., Pan, X., Komazaki, Y. Kurokawa, J., and Ohara, T.: Sensitivity analysis of source regions to $\mathrm{PM}_{2.5}$ concentration at Fukue island, Japan, J. Air Waste Manage., 64, 445-452, 2014.

Itahashi, S., Yumimoto, K., Uno, I., Eguchi, K., Takemura, T., Hara, Y., Shimizu, A., Sugimoto, N., and Liu, Z.: Structure of dust and air pollutant outflow over East Asia in the spring, Geosphys. Res. Lett., 37, L20806, doi:10.1029/2010GL044776, 2010.

Itahashi, S., Uno, I., and Kim, S-T.: Source contributions of sulfate aerosol over East Asia estimated by CMAQ-DDM, Environ. Sci. Technol., 46, 6733-6741, 2012.

Itahashi, S., Uno, I., and Kim, S.-T.: Seasonal source contributions of tropospheric ozone over East Asia based on CMAQ-HDDM, Atmos. Environ., 70, 204-217, 2013.

Itahashi, S., Uno, I., Hayami, H., and Fujita, S.: Modeling investigation of controlling factors in the increasing ratio of nitrate to non-seasalt sulfate in precipitation over Japan, Atmos. Environ., 92, 171-177, 2014.

Itahashi, S., Hayami, H., and Uno, I.: Comprehensive study of emission source contributions for tropospheric ozone formation over East Asia, J. Geophys. Res., 120, 331-358, 2015.

Itahashi, S., Hayami, H., Uno, I., Pan, X., and Uematsu, M.: Importance of coarse-mode nitrate produced via sea-salt as atmospheric input to East Asian oceans, Geophys. Res. Lett., 43, 5483-5491, 2016.

Itahashi, S., Hayami, H., Yumimoto, K., and Uno, I.: Chinese province-scale source apportionments for sulfate aerosol evaluated by the tagged tracer method in 2005, Environ. Pollut., 118, 87-97, 2017.

Irie, H., Muto, T., Itahashi, S., Kurokawa, J., and Uno, I.: Turnaround of tropospheric nitrogen dioxide pollution trends in China, Japan, and South Korea, SOLA, 12, 170-174, 2016.
Japan Meteorological Agency (JMA): http://www.data.jma.go.jp/ svd/vois/data/tokyo/volcano.html, last access: 14 January 2016 (in Japanese).

John, W., Hering, S., Reischl, G., Sasaki, G., and Goren, S.: Characteristics of Nuclepore Filters with Large pore size-II. Filtration Properties, Atmos. Environ., 17, 373-382, 1983.

Kajino, M., Sato, K., Inomata, Y., and Ueda, H.: Source-receptor relationships of nitrate in Northeast Asia and influence of sea salt on the long-range transport of nitrate, Atmos. Environ., 70, 67-78, 2013.

Kanaya, Y., Taketani, F., Komazaki, Y., Liu, X., Kondo, Y., Sahu, L. K., Irie, H., and Takashima, H.: Comparison of black carbon mass concentrations observed by multi-angle absorption photometer (MAAP) and continuous soot-monitoring system (COSMOS) on Fukue island and in Tokyo, Japan, Aerosol Sci. Tech., 47, 1-10, 2013.

Kanaya, Y., Pan, X., Miyakawa, T., Komazaki, Y., Taketani, F., Uno, I., and Kondo, Y.: Long-term observations of black carbon mass concentrations at Fukue Island, western Japan, during 2009-2015: constraining wet removal rates and emission strengths from East Asia, Atmos. Chem. Phys., 16, 1068910705, doi:10.5194/acp-16-10689-2016, 2016.

Kaneyasu, N., Yamamoto, S., Sato, K., Takami, A., Hayashi, M., Hara, K., Kawamoto, K., Okuda, T., and Hatakeyama, S.: Impact of long-range transport of aerosols on the $\mathrm{PM}_{2.5}$ composition at a major metropolitan area in the northern Kyushu area of Japan, Atmos. Environ., 97, 416-425, 2014.

Khoder, M. I.: Atmospheric conversion of sulfur dioxide to particulate sulfate and nitrogen dioxide to particulate and gaseous nitric acid in an urban area, Chemopshere, 49, 675-684, 2002.

Kimoto, H., Ueda, A., Tsujimoto, K., Mitani, Y., Toyazaki, Y., and Kimoto, T.: Development of a Continuous Dichotomous Aerosol Chemical Speciation Analyzer, Clean Technology, 23, 49-52, 2013 (in Japanese).

Kurokawa, J., Ohara, T., Morikawa, T., Hanayama, S., JanssensMaenhout, G., Fukui, T., Kawashima, K., and Akimoto, H.: Emissions of air pollutants and greenhouse gases over Asian regions during 2000-2008: Regional Emission inventory in ASia (REAS) version 2, Atmos. Chem. Phys., 13, 11019-11058, doi:10.5194/acp-13-11019-2013, 2013.

Li, H., Duan, F., He, K., Ma, Y., Kimoto, T., and Huang, T.: Sizedependent characterization of atmospheric particles during winter in Beijing, Atmosphere, 7, 36, doi:10.3390/atmos7030036, 2016.

Li, M., Zhang, Q., Kurokawa, J.-I., Woo, J.-H., He, K., Lu, Z., Ohara, T., Song, Y., Streets, D. G., Carmichael, G. R., Cheng, Y., Hong, C., Huo, H., Jiang, X., Kang, S., Liu, F., Su, H., and Zheng, B.: MIX: a mosaic Asian anthropogenic emission inventory under the international collaboration framework of the MICS-Asia and HTAP, Atmos. Chem. Phys., 17, 935-963, doi:10.5194/acp17-935-2017, 2017.

Ministry of Environment: http://www2.env.go.jp/pm25monitoring/ index.html, last access: 8 November 2016 (in Japanese).

Morino, Y., Ohara, T., and Nishizawa, M.: Atmospheric behavior, deposition, and budget of radioactive materials from the Fukushima Daiichi nuclear power plant in March 2011, Geophys. Res. Lett., 38, L00G11, doi::10.1029/2011GL048689, 2011. 
Morino, Y., Nagashima, T., Sugata, S., Sato, K., Tanabe, K., Noguchi, T., Takami, A., Tanimoto, H., and Ohara, T.: Verification of chemical transport model for $\mathrm{PM}_{2.5}$ chemical composition using simultaneous measurement data over Japan, Aerosol Air Qual. Res., 15, 2009-2023, 2015.

Nagashima, T., Ohara, T., Sudo, K., and Akimoto, H.: The relative importance of various source regions on East Asian surface ozone, Atmos. Chem. Phys., 10, 11305-11322, doi:10.5194/acp10-11305-2010, 2010.

Osada, K., Ueda, S., Egashira, T., Takami, A., and Kaneyasu, N.: Measurement of gaseous $\mathrm{NH}_{3}$ and particulate $\mathrm{NH}_{4}^{+}$in the atmosphere by fluorescent detection after continuous air-water droplet sampling, Aerosol Air Qual. Res., 11, 170-178, 2011.

Osada, K., Kamiguchi, Y., Yamamoto, S., Kuwahara, S., Pan, X., Hara, Y., and Uno, I.: Comparison of ionic concentrations on size-segregated atmospheric aerosol particles based on a denuder-filter method and a continuous dichotomous Aerosol Chemical Speciation Analyzer (ACSA-12), Earozoru Kenkyu, 31, 203-209, doi:10.11203/jar.31.203, 2016 (in Japanese with English abstract)

Pan, X., Uno, I., Hara, Y., Osada, K., Yamamoto, S., Wang, Z., Sugimoto, N., Kobayashi, H., and Wang, Z.: Polarization properties of aerosol particles over western Japan: classification, seasonal variation, and implications for air quality, Atmos. Chem. Phys., 16, 9863-9873, doi:10.5194/acp-16-9863-2016, 2016.

Pan, X. L., Kanaya, Y., Wang, Z. F., Liu, Y., Pochanart, P., Akimoto, H., Sun, Y. L., Dong, H. B., Li, J., Irie, H., and Takigawa, M.: Correlation of black carbon aerosol and carbon monoxide in the high-altitude environment of Mt. Huang in Eastern China, Atmos. Chem. Phys., 11, 9735-9747, doi:10.5194/acp-11-97352011, 2011.

Pan, Y., Tian, S., Liu, D., Fang, Y., Zhu, X., Zhang, Q., Zheng, B., Michalski, G., and Wang, Y.: Fossil fuel combustion-related emissions dominate atmospheric ammonia sources during severe haze episodes: Evidence from ${ }^{15} \mathrm{~N}$-stable isotope in sizeresolved aerosol ammonium, Environ. Sci. Technol., 50, 80498056, 2016.

Pandis, S. N. and Seinfeld, J. H.: Sensitivity analysis of a chemical mechanism for aqueous-phase atmospheric chemistry, J. Geophys. Res., 94, 1105-1126, 1989.

Perrino, C., Santis, F. D., and Febo, A.: Criteria for the Choice of a Denuder Sampling Technique Devoted to the Measurement of Atmospheric Nitrous and Nitric Acids, Atmos. Environ., 24, 617-626, 1990.

Petzold, A., Schloesser, H., Sheridan, P. J., Arnott, W. P., Ogren, J. A., and Virkkula, A: Evaluation of multiangle absorption photometry for measuring aerosol light absorption, Atmos. Sci. Technol., 39, 40-51, 2005.

Pinder, R. W., Dennis, R. L., and Bhave, P. V.: Observable indicators of the sensitivity of $\mathrm{PM}_{2.5}$ nitrate to emission reductions - Part I: Derivation of the adjusted gas ratio and applicability at regulatory-relevant time scales, Atmos. Environ., 42, 1275-1286, 2008.

San Martini, F. M., Hasenkopf, C. A., and Roberts, D. C.: Statistical analysis of $\mathrm{PM}_{2.5}$ observations from diplomatic facilities in China, Atmos. Environ., 110, 174-185, 2015.
Schultz, M. G., Heil, A., Hoelzemann, J. J., Spessa, A., Thonicke, K., Goldammer, J. G., Held, A. C., Pereira, J. M. C., and van het Bolscher, M.: Global wildland fire emissions from 1960 to 2000, Global Biogeochem. Cy., 22, GB2002, doi:10.1029/2007GB003031, 2008.

Seinfeld, J. H. and Pandis, S. N: Atmospheric Chemistry and Physics - From Air Pollution to Climate Change, 2nd Edn., John Wiley \& Sons, New York, USA, 2006.

Shimadera, H, Hayami, H., Chatani, S., Morino, Y., Mori, Y., Morikawa, T., Yamaji, K., and Ohara, T.: Sensitivity analyses of factors influencing CMAQ performance for fine particulate nitrate, J. Air Waste Manage., 64, 374-387, 2014.

Sickles II, J. E., Hodson, L. L., and Vorburger, L. M.: Evaluation of the filter pack for long-duration sampling of ambient air, Atmos. Environ., 33, 2187-2202, 1999.

Skamarock, W. C., Klemp, J. B., Dudhia, J., Gill, D. D., Barker, D. M., Duda, M. G., Huang, X-Y., Wang, W., and Powers, J. G.: A description of the advanced research WRF version 3, NCAR Tech. Note, NCAR/TN-475+STR, 113 pp., Natl. Cent. for Atmos. Res., Boulder, Colorado, USA, 2008.

Stein, A. F., Draxler, R. R., Rolph, G. D., Stunder, B. J. B., Cohen, M. D., and Ngan, F.: NOAA's HYSPLIT atmospheric transport and dispersion modeling system, B. Am. Meteorol. Soc., 96, 2059-2077, 2015.

Streets, D. G., Bond, T. C., Carmichael, G. R., Fernandes, S. D., Fu, Q., He, D., Klimont, Z., Nelson, S. M., Tsai, N. Y., Wang, M. Q., Woo, J.-H., and Yarber, K. F.: An inventory of gaseous and primary aerosol emissions in Asia in the year 2000, J. Geophys. Res.-Atmos., 108, 8809, doi:10.1029/2002JD003093, 2003.

Uno, I., Sugimoto, N., Shimizu, A., Yumimoto, K, Hara, Y., and Wang, Z.: Record Heavy $\mathrm{PM}_{2.5}$ air pollution over China in January 2013: Vertical and horizontal dimensions, SOLA, 10, 136140, 2014.

Vecchi, R., Valli, G., Fermo, P., D’Alessandro, A., Piazzalunga, A., and Bernardoni, V.: Organic and Inorganic Sampling Artefacts Assessment, Atmos. Environ., 43, 1713-1720, 2009.

Wang, H., Tan, S. C., Wang, Y., Jiang, C., Shi, G.-Y., Zhang, M.-X., and Che, H.-Z.: A multisource observation study of the severe prolonged regional haze episode over eastern China in January 2013, Atmos. Environ., 89, 807-815, 2014.

Xia, Y., Zhao, Y., and Nielsen, C. P.: Benefits of China's efforts in gaseous pollutant control indicated by the bottom-up emissions and satellite observations 2000-2014, Atmos. Environ., 136, 43 53, 2016.

Ying, Q., Wu, L., and Zhang, H.: Local and inter-regional contributions to $\mathrm{PM}_{2.5}$ nitrate and sulfate in China, Atmos. Environ., 94, 582-592, 2014.

Zhang, M., Gao, L., Ge, C., and Xu, Y.: Simulation of nitrate aerosol concentrations over East Asia with the model system RAMSCMAQ, Tellus, 59, 372-380, 2007.

Zheng, G. J., Duan, F. K., Su, H., Ma, Y. L., Cheng, Y., Zheng, B., Zhang, Q., Huang, T., Kimoto, T., Chang, D., Pöschl, U., Cheng, Y. F., and He, K. B.: Exploring the severe winter haze in Beijing: the impact of synoptic weather, regional transport and heterogeneous reactions, Atmos. Chem. Phys., 15, 2969-2983, doi:10.5194/acp-15-2969-2015, 2015. 